NBER WORKING PAPER SERIES

\title{
ESTIMATING INTERDEPENDENCE BETWEEN HEALTH AND EDUCATION IN A DYNAMIC MODEL
}

\author{
Li Gan \\ Guan Gong \\ WORKING PAPER 12830 \\ http://www.nber.org/papers/w12830 \\ NATIONAL BUREAU OF ECONOMIC RESEARCH \\ 1050 Massachusetts Avenue \\ Cambridge, MA 02138 \\ January 2007
}

This research was partially supported by NICHD grant 1 RO3 HD046892. Comments from Stephen Trejo and Russ Cooper are appreciated. All remaining errors are ours. The views expressed herein are those of the author(s) and do not necessarily reflect the views of the National Bureau of Economic Research.

(C) 2007 by Li Gan and Guan Gong. All rights reserved. Short sections of text, not to exceed two paragraphs, may be quoted without explicit permission provided that full credit, including ( $)$ notice, is given to the source. 
Estimating Interdependence Between Health and Education in a Dynamic Model

Li Gan and Guan Gong

NBER Working Paper No. 12830

January 2007

JEL No. C61,I12

\section{ABSTRACT}

This paper investigates to what extent and through which channels that health and educational attainment are interdependent. A dynamic model of schooling, work, health expenditure, and savings is developed. The structural framework explicitly models two existing hypotheses on the correlation between health and education. The estimation results strongly support the interdependence between health and education. In particular, the estimated model indicates that an individual's education, health expenditure, and previous health status all affect his health status. Moreover, the individual's health status affects his mortality rate, wage, home production, and academic success. On average, having been sick before age 21 decreases the individual's education by 1.4 years. Policy experiments indicate that a health expenditure subsidy would have a larger impact on educational attainment than a tuition subsidy.

Li Gan

Department of Economics

Texas A\&M University

College Station, TX 77843-4228

and NBER

gan@econmail.tamu.edu

Guan Gong

Shanghai University

of Finance and Economics

777 Guoding RD, Shanghai

CHINA

ggong@shufe.edu.cn 


\section{Introduction}

The highly positive correlation between health and education has been well documented in numerous literatures. ${ }^{1}$ This finding is robust even after controlling for different measures of socio-economic status, such as income and race, and regardless of whether health levels are measured by mortality rates, self-reported health status, or physiological indicators of health.

This paper studies the existing two competing explanations of this correlation. ${ }^{2}$ The first explanation argues that education improves health by raising economic conditions in per capita income so that a higher expenditure in health is possible and/or by increasing knowledge of health issues (Grossman 1975, Kenkel 1991, Rosenzweig and Schultz 1991). This explanation suggests that more education is the cause of better health. The second explanation argues the reverse causality, i.e., better health results in more education; healthier students may be more efficient in studying (Perri 1984, Currie and Hyson 1999). Better health may also increase the demand for education because of longer life expectancy (Gan and Gong 2004).

Clearly, these two explanations may not be mutually exclusive. The purpose of this paper is to study to what extent and through which channels that health and educational attainment are interdependent. In this paper, we estimate a dynamic programming model of joint decisions of young men on schooling, work, health expenditure, and savings. The structural framework explicitly models the correlations between health and education in the existing theoretical hypotheses, and thus the structural approach provides us a possibility to evaluate relative importance of alternative hypotheses. Moreover, the estimated model is used to evaluate the effects of policies such as financial support in health expenditure and/or in college education on an individual's health, education, and wealth.

Previous empirical studies on the correlation between health and education are typically based on the models with a static setting. The static setting creates at least two

${ }^{1}$ See Grossman and Kaestner (1997) for an extensive review.

2 A third explanation argues the existence of a "third factor" that affects both health and education in the same direction. For example, Fuchs (1982) states that time discount rates could be an explanation for the correlation between health and education: patient people would highly value future income and health -- and thereafter invest more in education and spend more time and money on activities related to health -- while impatient people would invest less in education and health. 
problems. First, since schooling and health are inherently endogenous, finding proper and reliable instruments for either health or schooling is often difficult. Second, a typical static model will have difficulty describing individuals who may have distinctive paths even if they experience similar shocks. For example, a low academic ability creates a higher risk of reaping the wage benefits of schooling and a higher probability of failing a grade. When facing a negative health shock, an individual with a lower academic ability may choose to drop out of school. His path in consumption, health status, and working, therefore, may differ systematically from those who have high academic abilities but have similar negative health shocks.

This paper develops a dynamic model with an uncertain environment. The model allows for heterogeneity among youth aged 16 in market skills, study skills, and health status. $^{3}$ The heterogeneity may be either innate or a result of prior parental and youth investment behavior. The model contains a number of channels that can account for interactive effects between health and educational attainment. First, the model allows the possibility that education may affect the chance of getting sick, as more educated people are more efficient producers of health. ${ }^{4}$ In addition, since an individual's wage depends on his education, the individual's education has an indirect effect on his health expenditure. Therefore, in both cases, more education may lead to better health.

Second, health is assumed to affect academic performance. The probability for an individual to pass or fail a grade depends not only on his academic ability but also on his health. Here, better health improves the productivity of the study and hence increases the educational attainment. Similarly, the model also assumes that health affects productivities at work and at home and therefore affects wages at work and output in home production.

Third, health is assumed to affect future survival rate. Sickness decreases the survival rate and thus reduces the effective time discount rate, which may result in less school

\footnotetext{
3 The sample selection of respondents above age 16 is based on the Fair Labor Standards Act (FLSA).

${ }^{4}$ The efficiency effect, discussed in detail by Grossman (1999), can take two forms: productive efficiency and allocative efficiency. Productive efficiency pertains to a situation in which the more educated obtain a larger health output from given amounts of endogenous (choice) inputs. Allocative efficiency pertains to a situation in which schooling increases information about the true effects of the input on health (Kenkel 2000). Allocative efficiency will improve health to the extent that it leads to the selection of a better input mix.
} 
attendance since the individual values his current consumption higher at the expense of his investment in the future. Although a reduction in survival rate and thus a reduction in effective time discount rate may be viewed as the third factor (Fuchs 1982, also see footnote \#2) that reduces both health and education, the reduction in survival rate is still caused by health.

Finally, the individual's future health status is dependent on his past and current health statuses. The individual is assumed to be constantly at risk of sickness. Current health status affects future health because it indicates an individual's physical and mental constitution and therefore implies future health. Grossman (1972) suggests health to be a stock variable. Allowing past and current health statuses to affect future health status captures an important aspect of health as a stock variable.

The model is estimated using data from the 1979 youth cohort of the National Longitudinal Surveys of Youth (NLSY79). For a representative sample of youth beginning at age 16, the data set provides longitudinal information on school enrollment, grade transcripts, work status, wages, assets, sickness, and the duration of sickness.

Estimation of the model strongly supports the interdependence between health and education because the coefficients that correspond to two hypotheses are all significantly estimated. In particular, the estimated sickness function indicates that an individual's probability of being sick is affected by his education, his health expenditure, and his previous health status. Moreover, health has a substantial effect on an individual's mortality rate, wages, home production, and academic success in school. Indeed, health plays an extremely important role in determining an individual's educational attainment. On average, having been sick before the age of 21 decreases education by 1.4 years.

Finally, the estimated model is used to perform two policy experiments: a direct college tuition subsidy and a high school health expenditure subsidy. To assess the efficiency of the policies, we let these two experiments have the same per capita cost. The results reveal that a health expenditure subsidy would have a larger impact on educational attainment than a direct college tuition subsidy. More specifically, a direct health expenditure subsidy of $\$ 2,100$ increases education by $24.3 \%$ more than a tuition subsidy of the similar cost. In addition, a direct college tuition subsidy will favor healthy individuals, especially those healthy and having low academic ability, while a subsidy of 
high school health expenditure will favor sick individuals, especially those sick and having high academic ability.

Since the NLSY does not contain direct observations on health expenditure, the model has to infer the amounts of health expenditures from the individuals' trajectories of asset accumulations and their choice decisions, such as work and school attendance. A key assumption for identifying the unobserved health expenditures is that only the individuals whose incomes are above a minimum level have health expenditure. Below this minimum level, the individual's primary concern is the consumption of necessary commodities. The minimum income level is exogenous to the individual, although it is estimated as a parameter in the structure model. Therefore, it is possible to identify the health expenditure by comparing the different paths of asset accumulation among high-income groups who spend on health and low-income groups who do not.

The estimation of the model applies the recently developed method of generalized indirect inference (GII) (Gourieroux, Monfort, and Renault, 1993; Keane and Smith, 2003). Typically, dynamic discrete choice models are estimated using maximum likelihood (ML) or method of moments (MOM). When the number of alternatives is large, evaluation of choice probability required by ML or MOM is computationally burdensome, because the choice probability is a high dimensional integral over stochastic factors that affect the individual's utility at each alternative. In addition, unobserved initial conditions, unobserved state variables, and variables with missing data may also create computational problems. In this paper, many initial conditions and state variables are unobserved. Asset information for 1979 -1984 and 1991 and transcript records beyond high school are missing.

Indirect inference provides a practical simulation-based approach to the estimation of dynamic discrete (or discrete/continuous) choice models with a large number of alternatives. This approach builds on the indirect inference, the idea of which is to use a rather simple descriptive statistical model to summarize the statistical properties of the observed data and the simulated data from the structural economic model. The method then chooses the structural parameters so that the coefficients of the descriptive statistical model in the simulated data match as closely as possible with those in the observed data. Since indirect inference is based on simulated data, it avoids the need to construct the 
choice probabilities generated by the model. However, the implementation of indirect inference in a discrete choice model encounters a serious problem because of the non-smooth objective function. GII overcomes this obstacle by using a continuous function with a smoothing parameter of the latent utilities as the dependent variable in the descriptive statistical model. As the smoothing parameter goes to zero, this function delivers the discrete choice implied by the latent utilities, and therefore guarantees consistency of the estimated parameters.

The paper is organized as follows. Section 2 presents the model, its basic structure, solution method, estimation method, and parameterization. Section 3 describes the data. Section 4 presents the estimation results and describes the policy applications. Section 5 concludes the paper.

\section{Model}

The model corresponds to the decision problem of a young man beginning at age 16 . At each period, he decides to be in one of three states: working, schooling, or staying at home. In addition, he will decide the amounts of health expenditure and saving. This section presents the structure of the model with the environment settings, the solution of the model, and the estimation method.

\subsection{Basic structure}

\subsubsection{Choice set}

The element of an individual's choice set at each age $t$ consists of a combination of activity choice $d_{t}^{1}$, asset $d_{t}^{2} d_{1, t}^{1}$, and health expenditure $d_{t}^{3}$. The individual chooses one of three states: working, schooling, or staying at home. The activity choice vector $d_{t}^{1}$ hence has three dummy variables: $d_{1, t}^{1}=1$ if the individual chooses to work at period $t$, otherwise $d_{1, t}^{1}=0 ; d_{2, t}^{1}$ and $d_{3, t}^{1}$ correspond to going to school or staying at home. Their values are similarly defined as $d_{1, t}^{1}$. At each age $t, \sum_{j=1}^{3} d_{j, t}^{1}=1$.

In addition, the individual at each age will choose level of asset. To improve the tractability of the problem, the continuous asset level is discretized into $K$ fixed number 
of discrete levels of saving, $\left\{\Delta A^{1}, \Delta A^{2}, \ldots, \Delta A^{K}\right\}$, where $A$ is the level of asset, and $\Delta A_{t+1}=A_{t+1}-(1+r) A_{t}$. The asset choice vector $d_{t}^{2}$ includes $K$ mutually exclusive alternatives, with $\sum_{k=1}^{K} d_{k, t}^{2}=1$, i.e., $d_{k, t}^{2}=1$ if $\Delta A^{k}$ is chosen, otherwise $d_{k, t}^{2}=0$. Thus, in this setup, the feasible asset may only grow with age $t$. It is necessary to note that net borrowing is not ruled out since $\Delta A$ may be less than zero.

Finally, the continuous health expenditure is also divided into the $M$ fixed number of discrete levels that are not less than zero: $\left\{h^{1}, h^{2}, \ldots, h^{M}\right\}$. Denote $1 \times M$ vector $d_{t}^{3}$ as the decision on the level of health expenditure with $\sum_{k=1}^{M} d_{m, t}^{3}=1$, i.e., $d_{m, t}^{3}=1$ if $h^{m}$ is chosen, otherwise $d_{m, t}^{3}=0$.

In summary, given the three choice vectors $d_{t}^{1}, d_{t}^{2}$, and $d_{t}^{3}$, the number of the individual's choice set at each age $t$ is $3 \times K \times M$.

\subsubsection{Environment settings}

In order to understand how the individual chooses alternatives in response to the current information set and stochastic shocks, it is useful to first describe the environment settings.

Individuals differ in their skill endowments, health statuses, and schoolings. At each age, individuals make choices among mutually exclusive and exhaustive alternatives on activity choices of school, work, or home, on net saving, and on health expenditure. The current health statuses and the current incomes from work and home have stochastic elements that are known to the individuals prior to the current-period decision but are unknown prior to the beginning of the current period. Although the individuals do not know if they will succeed in school before making the decision of whether or not to attend school, they know the probability of passing or failing the grade. Individuals may take divergent paths of schoolings, work, home, saving, and health expenditures because of the cumulative effects of various shocks, and because they have heterogeneous skill endowments and heterogeneous initial health status.

Figure 1 illustrates the order in which stochastic shocks happen and the timing of an 
individual's choices on alternatives. At the beginning of age $t$, the individual's health status (sick or healthy) is known, and the random shocks to wage and home production are realized. Then the individual chooses alternatives from among a combination of activity choices, the levels of saving, and the levels of health expenditure. If he is in school, the individual will receive a shock for the grade, which will impact his passing or failing the grade. At the end of period $t$, the agent will get a health shock, which, together with his prior educational attainment and current health expenditure, will determine his health at age $t+1$. The whole pattern at age $t$ is repeated at age $t+1$.

\subsubsection{Dynamic programming}

At each period $t$, the individual is assumed to maximize the present discounted value of lifetime utility from age $16(t=1)$ to a known terminal age, $t=T$. The value function is given by:

$$
V_{t}\left(\Omega_{t}\right)=\operatorname{Max} E\left[\sum_{s=t}^{T} \delta^{s-t} u\left(c_{s}\right) P_{s \mid t} \mid \Omega_{t}\right]
$$

where $E$ is the expectation operator, $\delta$ is the subjective time discount factor, and $u\left(c_{s}\right)=c_{s}^{1-\rho} /(1-\rho)$ is the contemporary utility at age $s . P_{s \mid t}$ is the conditional survival rate at age $s$ based on the information set at age $t$. The information set $\Omega_{t}$, known at the beginning of age $t$, includes age, educational attainment, working experience, health, accumulated assets, and contemporaneous shocks from wage and home production. The maximization of the objective function (1) is achieved by choices of the optimal sequence

of feasible control variables $\left\{d_{s}^{1}, d_{s}^{2}, d_{s}^{3}\right\}$, given current realizations of health and grade shocks.

The budget constraint for the individual is given by:

$$
c_{t}+\Delta A_{t+1}=w_{t} d_{1, t}^{1}+e_{t} d_{3, t}^{1}-e c * I\left(e d u_{t}>12\right) * d_{2, t}^{1}-h_{t},
$$

where $w_{t}$ is wage, $e_{t}$ is home production including compensation for not working, and $h_{t}$ is the health expenditure. $e d u$ is the level of educational attainment. The cost of education, denoted as $e c$, is assumed to be zero when $e d u$ is less than 12 years (completion of high school). Note that in this paper, educational attainment and years of schooling are two different concepts. Years of schooling are the total years that the individual has attended 
school, while educational attainment is the effective years of schooling, i.e., the total years of schooling minus the number of grades that an individual fails.

Health expenditure, such as spending on appropriate nutrition, vacation, and health clubs, affects an individual's survival. To make the model tractable, we do not model the individual's choice decision on health insurance and its subsequent effect on an individual's behavior. ${ }^{5}$ As stated above, the identification of health expenditure comes from a threshold of income. Only after the income is larger than this threshold will the individual spend on health. More specifically, let $N I B$ be the income boundary, such that the health expenditure is strictly positive, if $r A_{t}+w_{t} d_{1, t}^{1}+e_{t} d_{3, t}^{1}>N I B$, and zero otherwise.

Initial conditions at each age include health status, the level of educational attainment and the years of work experience at the beginning of the age. The level of asset accumulation up to the age is also part of the initial conditions. Both work experience and the level of asset at age 16 are assumed to be zero.

\subsubsection{Probability of sickness}

Health status in the next decision horizon is uncertain. The latent health status at age $t+1$, denoted as $H_{t+1}^{*}$, depends on his age, his present health expenditure, $h_{t}$, his educational attainment, $e d u_{t}$, and his health status at age $t$. Define:

$$
H_{t+1}^{*}=\beta_{1} \text { age }_{t+1}+\beta_{2} h_{t}+\beta_{3} e d u_{t+1}+D_{t}\left(\beta_{4}+\beta_{5} s l_{t}\right)+\varepsilon_{t+1}^{S},
$$

where $\varepsilon_{t+1}^{S}$ is the serially independent standard normal distribution. If the agent is not sick at age $t$, i.e., $D_{t}=0$, all his previous sick years will have no impact on his health status at age $t+1$. However, if the agent is sick, $D_{t}=1$, the number of continuous sick years up to age $t$, denoted as $s l_{t}$, may affect his health status at age $t+1{ }^{6}$ The parameter $\beta_{3}$ reflects the idea that more educated people may have better knowledge of health issues and thereby refrain from activities that are harmful to health. Then:

\footnotetext{
${ }^{5}$ Insured and uninsured people show many differences in behaviors related to health, including seatbelt use, diet, and exercise. Moreover, both the supply and demand for insurance depend on health status, which confounds the causal effect between insurance coverage and health. Indeed, evidence that access to health insurance causes better health is limited (Newhouse 1993; Levy and Meltzer, 2001).

${ }^{6}$ Equation (9.5) shows how the value of $s l_{t}$ is calculated.
} 
sick or $D_{t+1}=1$ if $H_{t+1}^{*}>0$,

not sick or $D_{t+1}=0$ if $H_{t+1}^{*} \leq 0$.

Note $H_{t+1}^{*}$ in (3) is related to but different from the health capital of Grossman (1972). To model Grossman's health capital, $H_{t+1}^{*}$ would have to depend on $H_{t}^{*}$. Since both $H_{t+1}^{*}$ and $H_{t}^{*}$ are unobserved, such a model would be difficult to estimate. Instead, we use an observed binary variable $D_{t}$ and an accumulative stock variable $s l_{t}$ to approximate $H_{t}^{*}$. Compared with the effect of the most current health status $D_{t}$, our estimation results show that the effect of $s l_{t}$ is very small.

\subsubsection{Survival rate}

Health, which is measured by the dummy of sickness, $D_{t}$, and the duration of prior sickness, $s l_{\mathfrak{t}}$, affects the individual's survival rate. The mortality rate $m_{t}$ is assumed to be:

$$
m_{t} \equiv-\frac{P_{t+1}-P_{t}}{P_{t}}=\left\{\begin{array}{cl}
\hat{m}_{t} e^{\alpha_{0}+D_{t}\left(\alpha_{1}+\alpha_{2} s l_{t}\right)}, & \text { if } \hat{m}_{t} e^{\alpha_{0}+D_{t}\left(\alpha_{1}+\alpha_{2} s l_{t}\right)}<1 \\
1, & \text { otherwise }
\end{array}\right.
$$

where $\hat{m}_{t}$ is the mortality rate of the life table at age $t$. Parameters $\alpha_{0}, \alpha_{1}$ and $\alpha_{2}$ measure the effect of health status on the individual's mortality if the individual was sick at the current age. Both $\alpha_{1}$ and $\alpha_{2}$ are expected to be positive. The mortality rate function in (3) implies that if the agent recovers from a previous period of illness, his current mortality risk will not be affected by his sickness during the previous period. However, if he is currently sick, the number of continuous sick years up to the current age will affect his current mortality risk. The survival rate at $t$, conditional on being alive at $s$, can thereby be written as:

$$
P_{s \mid t}=\left\{\begin{array}{cc}
\prod_{j=t}^{s-1}\left(1-m_{j}\right), & \text { as } \quad s>t \\
1, & \text { as } \quad s=t .
\end{array}\right.
$$

Note here that the identification of the mortality difference between the sick and the healthy is not from mortality risks at the individual levels. The current sample is too small to have enough observed deaths to allow reliable estimates. ${ }^{7}$ Rather, the

\footnotetext{
${ }^{7}$ From 1979 to 1994, there were only 19 deaths in the sample.
} 
identification comes from implied behavioral difference that leads to observed difference in outcomes.

\subsubsection{Passing or failing a grade}

When an individual is in school, he may pass or fail a grade. The individual may be a high study type (denoted as 1 ) or a low study type (denoted as 2 ). Whether he passes or fails a grade is assumed to depend on his study type; the duration of his previous sickness may also affect his school performance if he is currently sick. Let $\Phi_{t}^{*}$ be the latent academic performance variable,

$$
\Phi_{t}^{*}=\sum_{k=1}^{2} \xi_{0 k} I(\text { studytype }=k)+D_{t}\left(\xi_{1}+\xi_{2} s l_{t}\right)+\varepsilon_{t}^{G} .
$$

The serially independent random shock $\varepsilon_{t}^{G}$ follows a standard normal distribution. ${ }^{8}$ Then:

$$
\begin{gathered}
\text { pass if } \Phi_{t}^{*}>0, \\
\text { fail if } \Phi_{t}^{*} \leq 0
\end{gathered}
$$

In (6), the coefficients $\zeta_{1}$ and $\zeta_{2}$ are both expected to be negative since health may negatively affect the individuals' education attainment by affecting the quality of learning.

\subsubsection{Wage}

Assume that wage is a logarithm function of educational attainment (or effective schooling years), $e d u_{t}$, work skill type (high or low), work experience, $e p_{t}$, which is measured by cumulative years worked, age, health, and idiosyncratic shock $\varepsilon_{t}^{w}$ :

$$
\begin{aligned}
\ln w_{t}= & \sum_{k=1}^{2} \gamma_{0 k} I(\text { skill type }=k)+\gamma_{1} e d u_{t}+\gamma_{2} e p_{t}+\gamma_{3} e p_{t}^{2}+\gamma_{4} a g e_{t} \\
& +D_{t}\left(\gamma_{5}+\gamma_{6} s l_{t}\right)+\gamma_{7} I\left(e p_{t}=e p_{t-1}\right)+\varepsilon_{t}^{w},
\end{aligned}
$$

where the parameter $\gamma_{7}$ is the adjustment cost if the individual didn't work in the previous period. Skill types enter into the wage function to reflect the effect of different market

\footnotetext{
8 The unobserved random variable may include the individual's level of motivation in study and the quality of the teacher.
} 
skills on wages. Again, we assume that the duration of his previous sickness may affect his wages if he is currently sick.

\subsubsection{Home production}

The output of home production is unobserved to econometricians, but observed to the individuals. Any output that the individual produces to lower the household expenditure and any compensation he may receives when staying at home are included as the output of home production. To make it simple, the home production function is assumed to only depend on an individual's health:

$$
e_{t}=\bar{e}+D_{t}\left(\phi_{1}+\phi_{2} s l_{t}\right)+\varepsilon_{t}^{e},
$$

where $\bar{e}$ is constant and $\varphi_{1}$ and $\varphi_{2}$ are coefficients of health status. The shocks to the wage equation (7) $\varepsilon_{t}^{w}$ and $\varepsilon_{t}^{e}$ in (8) are serially independent and follow normal distributions. $\operatorname{Var}\left(\varepsilon_{t}^{w}\right)=\sigma_{w}^{2}, \operatorname{Var}\left(\varepsilon_{t}^{e}\right)=\sigma_{e}^{2}$, and $\operatorname{Cov}\left(\varepsilon_{t}^{w}, \varepsilon_{t}^{e}\right)=\sigma_{w e}^{2}$.

\subsubsection{Evolution of the state space variables}

The state space of this dynamic programming model at age $t$ is:

$\Omega_{t}=\left\{e d u_{t}, e p_{t}, A_{t}, D_{t}, s l_{t}, d_{t-1}^{1}, d_{t-1}^{2}, d_{t-1}^{3}, \varepsilon_{t}^{w}, \varepsilon_{t}^{e}\right\}$. Note that both the grade shock $\varepsilon_{t}^{G}$ and the health shock $\varepsilon_{t}^{S}$ are not included in the state space. As described in the environment settings and in Figure 1, $\varepsilon_{t}^{G}$ is only certain to the individual after the choice decision on school attendance has been made. The health shock $\varepsilon_{t}^{S}$, on the other hand, is known to the individual prior to the state decisions and its information is reflected in the sickness dummy, $D_{t}$.

It is important to describe how the elements of the state space evolve. We only describe the first five elements of the state space. The evolution of the rest elements is either obvious or independent across years. We start with $e d u_{t}$. The individual's education level increases by one year at age $t+1$ if and only if he attends school at age $t$ and he passes the grade, i.e.,

$$
e d u_{t+1}=\left\{\begin{array}{cc}
e d u_{t}+1, & \text { attendingschoolandpassingthegrade } \\
e d u_{t}, & \text { otherwise }
\end{array}\right.
$$


As noted earlier, the years of education is different from the years of schooling. An individual's education is increased by one year if he passes the grade.

The individual's working experience $e p_{t+l}$ increases by one year if and only if he works at age $t$ :

$$
e p_{t+1}=e p_{t}+d_{1, t}^{1} \text {. }
$$

The individual's asset at $t+1$ is the sum of his asset at the beginning of age $t$ and his choice of asset level at age $t$ :

$$
A_{t+1}=(1+r) A_{t}+\sum_{k=1}^{K} \Delta A^{k} d_{k, t}^{2} ;
$$

As illustrated in Figure 1, the sickness dummy at age $t+1, D_{t+1}$, takes value at the end of $t+1$, after the choice on health expenditure at $t$ and the education at $t+1$ occur (see equation (3) and Figure 1).

$$
D_{t+1}= \begin{cases}1, & \text { if sick } \\ 0, & \text { if not sick. }\end{cases}
$$

The variable $s l_{t}$ measures the duration of the current sickness up to age $t$ (not including age $t$ ). In particular, $s l_{t+1}$ has the following form:

$$
s l_{t+1}=D_{t}\left(s l_{t}+D_{t}\right) \text {. }
$$

From equation (9.5), $s l_{t+1}=0$ if $D_{t}=0$. Suppose the individual is sick at age $t$ and age $t$-1, but not sick at age $t-2$, then his $s l_{t+1}=1$.

\subsection{Solution method}

The maximization problem is set into a dynamic programming framework. The value function can be written as the maximum over alternative-specific value functions, each of which obeys the Bellman equation:

$$
V_{t}\left(\Omega_{t} ; \Psi\right)=\max _{i \in \Gamma}\left\{V_{t}^{i}\left(\Omega_{t} ; \Psi\right)\right\}
$$

where $\Psi$ is the parameter set of the structural model. $\Gamma$ is the Cartesian product set of alternatives $\mathrm{Z}=d^{1} \times d^{2} \times d^{3}$, which consists of $3 \times K \times M$ elements. The value function of the ith alternative, $V_{t}^{i}\left(\Omega_{t} ; \Psi\right)$, is given by: 


$$
\begin{aligned}
V_{t}^{i}\left(\Omega_{t} ; \Psi\right) & =u^{i}\left(\Omega_{t} ; \Psi\right)+\delta\left(1-m_{t}\right) E\left[V_{t+1}\left(\Omega_{t+1} ; \Psi\right) \mid \Omega_{t}, \mathrm{Z}_{t}^{i}=1\right] \\
& \equiv u^{i}\left(\Omega_{t} ; \Psi\right)+\delta\left(1-m_{t}\right) E \max _{t}\left(\Omega_{t+1} ; \Psi \mid \Omega_{t}, \mathrm{Z}_{t}^{i}=1\right) . \quad t<T
\end{aligned}
$$

The terminal value function of the $i t h$ alternative is given by:

$$
V_{T}^{i}\left(\Omega_{t} ; \Psi\right)=u^{i}\left(\Omega_{T} ; \Psi\right)+\delta\left(1-m_{T}\right) E\left[V_{T+1}^{*}\left(\Omega_{T+1} ; \Psi\right) \mid \Omega_{T}, Z_{T}^{i}=1\right] . \quad t=T
$$

In both (11) and (12), $u^{i}\left(\Omega_{t} ; \Psi\right)$ represents the contemporary utility if the ith alternative is chosen (i.e. $Z_{t}^{i}=1$ ). $V_{T+1}^{*}$ is the terminal function and will be discussed later. The $E \max _{t}$ function in (11) depends whether attending school or not. In particular:

If schooling is not chosen at age $t$, i.e, $d_{2, t}^{1}=0$, then:

$$
\begin{aligned}
E \max _{t} & \left.=\operatorname{Pr}_{t}\left(\text { sick } \mid \Omega_{t}, \mathrm{Z}_{t}^{i}=1\right) E\left|V_{t+1}\left(\Omega_{t+1} ; \Psi\right)\right| \Omega_{t}, \mathrm{Z}_{t}^{i}=1, \text { sick }\right] \\
& +\operatorname{Pr}_{t}\left(\text { healthy } \mid \Omega_{t}, \mathrm{Z}_{t}^{i}=1\right) E\left[V_{t+1}\left(\Omega_{t+1} ; \Psi\right) \Omega_{t}, \mathrm{Z}_{t}^{i}=1 \text {, healthy }\right] .
\end{aligned}
$$

If schooling is chosen, i.e. $d_{2, t}^{1}=1$, then:

$$
\begin{aligned}
E \max _{t} & =\operatorname{Pr}_{t}\left(\text { pass } \mid \Omega_{t}, Z_{t}^{i}=1\right) \operatorname{Pr}_{t}\left(\text { sick } \mid \Omega_{t}, Z_{t}^{i}=1\right) E\left[V_{t+1}\left(\Omega_{t+1} ; \Psi\right) \mid \Omega_{t}, \mathrm{Z}_{t}^{i}=1 \text {, pass, sick }\right] \\
& +\operatorname{Pr}_{t}\left(\text { fail } \mid \Omega_{t}, \mathrm{Z}_{t}^{i}=1\right) \operatorname{Pr}_{t}\left(\text { sick } \mid \Omega_{t}, \mathrm{Z}_{t}^{i}=1\right) E\left[V_{t+1}\left(\Omega_{t+1} ; \Psi\right) \mid \Omega_{t}, \mathrm{Z}_{t}^{i}=1, \text { fail, sick }\right] \\
& +\operatorname{Pr}_{t}\left(\text { pass } \mid \Omega_{t}, \mathrm{Z}_{t}^{i}=1\right) \operatorname{Pr}_{t}\left(\text { healthy } \mid \Omega_{t}, \mathrm{Z}_{t}^{i}=1\right) E\left[V_{t+1}\left(\Omega_{t+1} ; \Psi\right) \Omega_{t}, \mathrm{Z}_{t}^{i}=1, \text { pass, healthy }\right] \\
& +\operatorname{Pr}_{t}\left(\text { fail } \mid \Omega_{t}, \mathrm{Z}_{t}^{i}=1\right) \operatorname{Pr}_{t}\left(\text { healthy } \mid \Omega_{t}, \mathrm{Z}_{t}^{i}=1\right) E\left[V_{t+1}\left(\Omega_{t+1} ; \Psi\right) \mid \Omega_{t}, \mathrm{Z}_{t}^{i}=1, \text { fail, healthy }\right],
\end{aligned}
$$

Given the finite horizon, the solution method is conducted through backward recursion. The difficulty with this procedure is the well-known "curse of dimensionality" problem. When the dimension of the state space and the choice set are large, the solution of the model becomes computationally intractable. This is particularly true in the present structural model, since the choice set $d^{1} \times d^{2} \times d^{3}$ at each age contains $405(3 \times 15 \times 9)$ elements. ${ }^{9}$ As the time horizon increases, the state space increases exponentially. To deal with this problem, we adopt an approximation method in Keane and Wolpin (1994).

Specifically, at each age $t$, we first compute the $E \max _{t}$ function at a randomly selected subset of 200 state space points. For each of these state space points, we use the Monte Carlo integration to simulate the required multivariate integrals to obtain its $E_{m^{2}}$

${ }^{9}$ Fifteen possible values for net asset savings are $\pm(7,500,5,000,3,000,2,000,1,000,500)$ and 0 , 10,000 and 15,000). Nine possible values for health expenditure are $0,250,500,750,1,000,1,500$, $3,000,5,000,7,500$. 
value. Next, we estimate a polynomial regression function using these state space points. The functional form of the polynomial, denoted as $\overline{E \max }_{t}$, is given by:

$$
\begin{aligned}
\overline{E \max }_{t}=\lambda_{01}^{t}+\lambda_{02}^{t} I(\text { study type is high })+\lambda_{03}^{t} I(\text { work type is high })+D_{t}\left(\lambda_{1}^{t}+\lambda_{2}^{t} s l_{t}\right) \\
\quad+\lambda_{3}^{t} e d u_{t}+\lambda_{4}^{t} e d u_{t}^{2}+\lambda_{5}^{t} A_{t}+\lambda_{6}^{t} A_{t}^{2}+\lambda_{7}^{t} e p_{t}+\lambda_{8}^{t} e p_{t}^{2} \\
\quad+\lambda_{9}^{t} e d u_{t} I(\text { studytype is high })+\lambda_{10}^{t} e d u_{t} I(\text { work type is high }) \\
\quad+\lambda_{11}^{t} A_{t} I(\text { studytype is high })+\lambda_{12}^{t} A_{t} I(\text { work type is high }) \\
\quad+\lambda_{13}^{t} e p_{t} I(\text { studytype is high })+\lambda_{14}^{t} e p_{t} I(\text { work type is high }) .
\end{aligned}
$$

Finally, the $E \max _{\mathrm{t}}$ values at other non-simulated state space points are interpolated by using the predicted values based on estimated coefficients from the regression in (15.1). The process is repeated for each age, and the coefficients in (15.1) are age-dependent.

Solving the maximum problem requires specifying the terminal condition. The terminal age, $T=31$, is the maximum age of individuals in the sample. We use the polynomial form of the Emax function in (15.1) at the terminal age $T$ as the terminal condition. Since a different set of parameters is necessary, we explicitly list the terminal condition in (15.2):

$$
\begin{aligned}
V_{T+1}^{*} & =\tau_{01}+\tau_{02} I(\text { studytype is high })+\tau_{03} I(\text { work type is high })+D_{T+1}\left(\tau_{1}+\tau_{2} s l_{T+1}\right) \\
& +\tau_{3} e d u_{T+1}+\tau_{4} e d u_{T+1}^{2}+\tau_{5} A_{T+1}+\tau_{6} A_{T+1}^{2}+\tau_{7} e p_{T+1}+\tau_{8} e p_{T+1}^{2} \\
& +\tau_{9} e d u_{T+1} I(\text { studytype is high })+\tau_{10} e d u_{T+1} I(\text { work type } i \text { s high }) \\
& +\tau_{11} A_{T+1} I(\text { studytype is high })+\tau_{12} A_{T+1} I(\text { work type is high }) \\
& +\tau_{13} e p_{T+1} I(\text { studytype is high })+\tau_{14} e p_{T+1} I(\text { work type is high }) .
\end{aligned}
$$

The parameters of this terminal function are estimated along with the structural parameters of the model.

\subsection{Estimation method}

For any given set of structural parameters, one can simulate the outcomes of the model. A typical statistical estimation method obtains a set of parameters that directly matches the predicted outcomes with the observed outcomes. However, when the number of possible outcomes is large, it is often numerically very difficult to predict probabilities of each outcome because of the problem of high-dimensional integration. The approach 
of indirect inference (Gourieroux, Monfort, and Renault, 1993) first selects a simple descriptive statistical model. Instead of directly matching predicted outcomes and observed outcomes, the approach indirectly matches the coefficient estimates of the descriptive model from the simulated data with the ones from the observed data. By doing so, this approach avoids the problem of predicting probabilities of outcomes, since the simulated outcomes can be directly obtained because random draws are known to econometricians in each simulation. The application of GII (Keane and Smith, 2003) to estimate the dynamic programming problem in (10) can be implemented in four stages. This subsection describes the four-stage estimation method in detail.

\subsubsection{Stage 1: Estimate the descriptive statistical model using the observed data.}

The criteria for choosing an appropriate descriptive statistical model are computational tractability and statistical efficiency which it can provide a good description of the data. The linear probability models, as suggested by Keane and Smith (2003), fit the criteria precisely.

Denote $\left\{y_{i t}\right\}_{i=1}^{N}, t=1, \ldots, T$ as the observed choices and outcomes for individual $i$ and time $t$. The observed activity choices include working, attending school, or staying at home. The outcomes include passing/failing the grade, healthy/sick status, wages, and assets. Because some variables have missing data, and some state variables are unobserved, the content of $y_{i t}$ may be different across both individuals and ages. The descriptive statistical model is given by:

$$
y_{i t}=x_{i t} \eta_{t}+v_{t}, \quad v_{t} \sim \operatorname{iidN}\left(0, \sum_{t}\right),
$$

where $x_{t}$ is the vector of regressors, and $\theta_{t}=\left(\eta_{t}, \Sigma_{t}\right)$ is the set of parameters to be estimated. The details of selections of dependent variables $y_{i t}$ and independent variables $x_{i t}$ by age category are described in the Appendix.

Denote the likelihood function of the descriptive statistical model as $L(y ; z, \Theta)=\prod_{i=1}^{N} \prod_{t=1}^{T} l\left(y_{i t} ; x_{i t}, \theta_{t}\right)$, where $z$ is the observed exogenous initial variables, including health status, educational attainment, working experience, and assets. The initial values of both working experience and assets are zero. Let $\Theta$ be the parameter set $\left\{\theta_{t}\right\}_{t=1}^{T}$. The first step is to find the set of parameters that maximizes the likelihood 
function of the descriptive statistical model:

$$
\hat{\Theta}=\arg \max _{\Theta} L(y ; z, \Theta) .
$$

\subsubsection{Stage 2: Simulate the outcomes from the structural model}

We simulate the choices made for each individual from age 16 to 31. Given the initial condition $z$ and a set of structural parameters $\Psi$, the structural model can be used to generate statistically independent simulated data sets $\left\{\tilde{y}_{i t}^{f}(\Psi)\right\}_{i=1}^{N}$, where $f=1, \ldots, F$, $t=1, \ldots, T ; \quad N$ is the number of observations in each data set, and $F$ is the total number

of data sets. The vector of $\tilde{y}_{i t}$ and $y_{i t}$ consist of the same type of elements, such as state decisions (school, work, or home, $d_{t}^{1}$ ), indicators for passing a grade, sickness $D_{t}$, wages $w_{t}$, and assets $A_{t}$. The data sets $\left\{\tilde{y}_{i t}^{f}(\Psi)\right\}_{i=1}^{N}$ are generated based on the above described solution method of the simulation and interpolation for computing Emax. Each of the $F$ simulated data sets is constructed using the same set of observed exogenous individuals' initial variable $z$. The difference of each simulated data set results solely from the different sequences of error draws, which are held fixed for different values of the parameter $\Psi$.

\subsubsection{Stage 3: Estimate the descriptive statistical model using the simulated data}

Each of the simulated data sets can then be applied to estimate the descriptive statistical model of (16). However, it is not computationally practical to simply plug in the simulated discrete variables into the descriptive statistical model because of the non-smooth objective function (actually, its surface is a step function). ${ }^{10}$ Applying the idea of GII proposed in Keane and Smith (2003), we use a series of functions of latent utility to substitute the discrete choice variables. More specifically, we use the function

\footnotetext{
${ }^{10}$ The reason for the difficulty in practice is discussed in detail in Keane and Smith (2003): "small changes in the structural parameters $\Psi$ will cause the simulated data jump discretely and such a discrete change caused the parameters of the descriptive model fit to the simulated data to jump discretely. This jump, in turn causes the metric of distance between the descriptive models estimated on the observed and simulated data to jump discretely too. The algorithms to deal with the minimization of a non-smooth function perform very poorly.”
} 


$$
\widetilde{\widetilde{d}}_{1, t}^{1}(\Psi ; \lambda)=\frac{\sum_{j \in \Xi_{1}} \exp \left(V_{t}^{j}\left(\Omega_{t} ; \Psi\right) / \lambda\right)}{\sum_{j \in \Gamma} \exp \left(V_{t}^{j}\left(\Omega_{t} ; \Psi\right) / \lambda\right)}
$$

in place of simulated $\tilde{d}_{1, t}^{1}$, where $\Xi_{l}$ is a subset of $\Gamma$ and consists of all the alternatives in which job participation is chosen, and $\lambda$ is the smooth parameter. The functions $V_{t}^{j}\left(\Omega_{t} ; \Psi\right)$ are defined in (11) and (12). Because the latent utilities are smooth functions of the parameter set $\Psi, \widetilde{\widetilde{d}}_{1, t}^{1}(\Psi ; \lambda)$ is also a smooth function of $\Psi$. Moreover, as the smooth parameter $\lambda$ goes to zero, $\tilde{\widetilde{d}}_{1, t}^{1}(\Psi ; \lambda)$ goes to 1 if an alternative with job participation has the highest latent utility and to zero otherwise.

Similarly, we use the function

$$
\widetilde{\widetilde{d}}_{2, t}^{1}(\Psi ; \lambda)=\frac{\sum_{j \in \Xi_{2}} \exp \left(V_{1}^{j}\left(\Omega_{t} ; \Psi\right) / \lambda\right)}{\sum_{\Gamma} \exp \left(V_{1}^{j}\left(\Omega_{t} ; \Psi\right) / \lambda\right)}
$$

in place of simulated $\tilde{d}_{2, t}^{1}$, where subset $\Xi_{2}$ consists of all the alternatives in which school attendance is chosen. As the smooth parameter $\lambda$ goes to zero, $\widetilde{\tilde{d}}_{2, t}^{1}(\Psi ; \lambda)$ goes to 1 if an alternative with school attendance has the highest latent utility and to zero otherwise.

Wages are observed if and only if the individuals worked during that period. To make the simulated wage match the observed wage, we apply the observed wage for those individuals who worked during that period, and set the wage to zero for those individuals who did not work during that period. We use $\widetilde{\widetilde{d}}_{1, t}^{1}(\Psi ; \lambda) \widetilde{w}_{i t}(\Psi)$ in place of the simulated wage $\tilde{w}_{i t}(\Psi)$. Since both $\tilde{\widetilde{d}}_{1, t}^{1}(\Psi ; \lambda)$ and $\tilde{w}_{i t}(\Psi)$ are smooth functions of $\Psi$, the estimated parameters of the descriptive statistical model using the simulated data are also smooth functions of $\Psi$. Moreover, as the smoothing parameter $\lambda$ goes to 0 , $\tilde{\widetilde{d}}_{1, t}^{1}(\Psi ; \lambda) \tilde{w}_{i t}(\Psi)$ goes to $\tilde{w}_{i t}(\Psi)$ if an alternative with job participation choice has the highest latent utility and to zero otherwise.

Furthermore, because the sickness dummy is a discrete variable, it needs to be 
substituted by a continuous function. We use:

$$
\widetilde{\widetilde{D}}_{t+1}(\Psi ; \lambda)=\frac{\exp \left(H_{t+1}^{*}(\Psi) / \lambda\right)}{1+\exp \left(H_{t+1}^{*}(\Psi) / \lambda\right)}
$$

in place of simulated $\tilde{D}_{t+1}$. The latent variable $H_{t+1}^{*}(\Psi)$ (20) is defined in equation (3). Thus, as the smooth parameter $\lambda$ goes to $0, \tilde{D}_{t+1}(\Psi, \lambda)$ goes to 1 if $H_{t+1}^{*}>0$ and to zero otherwise.

Finally, according to the same reason for the discrete variable of sickness, we use the continuous function $\exp \left(\Phi_{t}^{*}(\Psi) / \lambda\right) /\left[1+\exp \left(\Phi_{t}^{*}(\Psi) / \lambda\right)\right]$ in place of the indicator for passing a grade, where the latent variable $\Phi_{t}^{*}(\Psi)$ is defined in equation (6).

Denote $\left\{\widetilde{\widetilde{y}}_{i t}^{f}(\Psi ; \lambda)\right\}_{i=1}^{N}, t=1, \ldots, T$, and $f=1, \ldots, F$ as the modified simulated data smoothed by using the functions of the latent utilities. The descriptive statistical model then can be estimated using each of the simulated smoothed data to obtain the following parameters:

$$
\widetilde{\widetilde{\Theta}}_{f}(\Psi ; \lambda)=\arg \max _{\Theta} L\left(\widetilde{\widetilde{y}}^{f}(\Psi ; z) ; x, \Theta\right)
$$

Let the average of the estimated parameters be $\widetilde{\widetilde{\Theta}}(\Psi ; \lambda)=\sum_{f=1}^{F} \widetilde{\widetilde{\Theta}}_{f}(\Psi ; \lambda) / F$. As the sample size $N$ goes to large and the smooth parameter $\lambda$ goes to small (zero), $\widetilde{\widetilde{\Theta}}(\Psi ; \lambda)$ converges to a nonstochastic "binding” function $H(\Psi)$ (Gourieroux, Monfort, and Renault 1993 and Keane and Smith, 2003). The next step of the GII is to get an estimate $\hat{\Psi}$ of the structural parameters so as to make $\widetilde{\widetilde{\Theta}}(\Psi ; \lambda)$ and $\hat{\Theta}$ as close as possible.

\subsubsection{Stage 4: Estimate the set of structural parameters $\Psi$.}

Estimates of the structural parameter $\Psi$ can be obtained by minimizing a metric function that measures the distance between $\hat{\Theta}$ and $\widetilde{\widetilde{\Theta}}(\Psi)$. In the present context, we adopt the likelihood ratio as the metric function, which is used in Keane and Smith (2003). In particular,

$$
\hat{\Psi}=\arg \max _{\Psi} L(y ; z, \widetilde{\widetilde{\Theta}}(\Psi ; \lambda))
$$


The two-step approach proposed by Keane and Smith (2003) is used to estimate the parameters of the structural model. The idea of the first step is to obtain a consistent estimate $\hat{\Psi}_{1}$ of the structural parameters by solving the optimization problem (22). In the first step, the number of simulated data sets $F$ is set to 1 , which substantially reduces the computation time. In addition, a relatively large value for the smoothing parameter $\lambda$ is chosen $(\lambda=0.05)$ to ensure the objective function is smooth.

In the second step, to reduce bias we choose $\lambda$ to be 0.003 and $F$ to be 100 . According to Proposition 2 in Keane and Smith (2003),

$$
\hat{\Psi}_{2}=\hat{\Psi}_{1}-\left(\hat{J}^{\prime} L_{\Theta \Theta}\left(y ; z, \widetilde{\widetilde{\Theta}}\left(\hat{\Psi}_{1}\right)\right) \hat{J}\right)^{-1} \hat{J}^{\prime} L_{\Theta \Theta}\left(y ; z, \widetilde{\widetilde{\Theta}}\left(\hat{\Psi}_{1}\right)\right)
$$

is a consistent and asymptotically normal estimate of $\Psi$, where $L_{\Theta \Theta}$ is the Hessian of the likelihood function associated with the descriptive model, and $\hat{J}$ is an estimate of the Jacobian of the binding function $H\left(\hat{\Psi}_{1}\right)$.

\section{Data}

The dataset used in this paper is from the 1979 youth cohort of the National Longitudinal Surveys of Youth (NLSY79). The NLSY79 contains extensive information about the individuals’ employment, education, health, income, and assets. An original 12,686 individuals were interviewed each year from 1979 to 1994. After 1994, the interviews switched to every other year. We use information from 1979 to 1994 . That gives us sixteen years of data to work with.

The analysis is based on the sample of the white males who were age 16 or younger as of October 1, 1977. Each individual in the sample is followed from the first year he reaches age 16 as of October 1 of that year to September 30, 1993. The females are excluded in this paper, since the fertility choice that young females face calls for a model that is substantially different from the current model. Black males are also excluded, since this group may also require a different model from white males (see, for example, Gan and Gong 2004). Finally, we exclude from our sample those who had any active military service. Modeling military service is not in the scope of this study. 


\subsection{Health}

In each survey year, the NLSY79 asked the individuals a standard set of health questions. The focus of these questions was on the health problems that affected the respondent's ability to work. In each year, if the respondents were not currently working, they were asked if their health would prevent them from working, and the rest of respondents who were currently working were asked if their health limited the type and the amount of work they could do. If a health limitation was reported, the NLSY79 then probed for the month and year the health limitation began.

We use the answers to these questions to construct the health variables. ${ }^{11}$ An individual was classified as being sick $\left(D_{t}\right)$ in a given year if a health limitation was reported in that year. The construction of the sick duration variable $\left(s l_{t}\right)$ is based on the information of when the individual's reported date that the sickness began. The difficulty in constructing health variables is that a large portion, around thirty percent, of the self-reported sick duration in the NLSY79 did not match the preceding self-reported sickness. For example, some respondents reported that the sickness began at some earlier point, for instance, two years ago, but no reported health limitation could be found during the last two years. This could be because that no surveys were conducted for these respondents at those years, or because that the respondents had not been aware of the sickness until the health limitations developed into a serious problem that affects their lives. To solve this problem of inconsistency, we check the subsequent self-reported answers to health questions, while also searching for references to the specific ailments. If the respondents kept reporting the same health problems and the same date the health limitation began, we then use this information to update the prior sickness variables. If the specific health problem was only reported once but the duration was longer than one year during the entire time of the survey, we simply classify the respondent as sick only during that reported year.

In the constructed health data, $21 \%$ of the respondents report at least one illness during the 16 years of surveys. The average duration is 2.28 years. Figure 2 shows the

\footnotetext{
${ }^{11}$ More specific details on health ailments were asked in the NLSY79 if the individuals gave affirmative answers that health limited either the kind or amount of work they could do.
} 
percentage of respondents who reported sickness at each age from 16 to $29 .^{12}$ At the early age of 16, 4.14\% of respondents consider themselves sick. Over the subsequent 15 years, the percentage of the respondents reporting an illness increases steadily, peaking at the age of 29 with $5.17 \%$.

\subsection{Schooling, work, or home}

At each interview date, the NLSY79 asked the respondents about their enrollment status, the highest grade attended and completed, the dates of leaving school, and the dates that diplomas and degrees were received. An individual is classified as attending school during the year if the individual reported enrollment in school at the time of the survey and did not report dropping out of school during that year in the subsequent surveys.

Employment data in the NLSY79 include the beginning and ending dates of all jobs, hours worked on each job, and salary paid on each job. An individual who does not attend school is classified as having worked during the year if the individual reported working at least 1,000 hours, i.e. at least 20 hours per week on average for 50 weeks

Finally, an individual is classified as being at home during the year if the individual was neither enrolled in school nor worked during the year. Note that some individuals would be classified as being at home if they worked during the year but did not work at least 1,000 hours.

Table 1 presents the choice distributions by age for the whole sample and for the sickness subsample. The sickness subsample is cumulative, i.e., at each age $t$, it consists of the individuals who have reported sickness at least once up to age $t$. The initial sample size is 1,062 at age 16 . From age 16 to age 29, the sample size declines slightly as a result of sample attrition such as deceases. The sample size falls from 1045 to 776 at ages 29 and 30, and from 776 to 463 at ages 30 and 31. This is because some respondents have not yet reached age 31 during the survey periods. Overall, there are 15,972 person-periods in the whole sample dataset and 2,198 person-periods in the sickness

12 The figure ends at age 29 instead of 31 . The percentages of sickness report at ages 30 and 31 are $4.81 \%$ and 5.18\%, respectively. A dip at age 30 and the breaking of the increase trend may come from the shrinking of sample size. During the annual survey from 1979 to 1993, 98.4\% of the original respondents reached age 28 ; however, only $73 \%$ and $43.6 \%$ of the respondents reach age 30 and 31 years old, respectively. 
subsample.

As table 1 shows, an individual's decisions on school attendance, job participation, or remaining home are highly correlated with the individual's health. Compared to the individuals in the whole sample, individuals in the sickness subsample at each age have a smaller percentage of attending school and a larger percentage of remaining home. Moreover, although a slightly larger percentage of individuals in the sickness data worked from age 16 to age 18, a relatively smaller percentage of sick individuals worked after that. More specifically, $11.56 \%$ of the individuals in the sickness subsample attended school, $42.81 \%$ worked, and $45.63 \%$ remained at home. The corresponding percentages for the individuals in the whole sample are $25.34 \%$, 54.46\%, and $20.20 \%$. Furthermore, the relative difference in the percentage of school attendance between the two data sets increases during the normal schooling ages. For example, at age 16, the percentage of individuals attending school while having been sick is $81.82 \%$ (i.e., $93.6 \%$ of the average $87.38 \%$ ), but at the normal high school graduation age of 18 , that percentage drops to $38.55 \%$ (i.e., $77.2 \%$ of the average $49.95 \%$ ); at the normal college graduation age of 22, it drops to $11.51 \%$ (i.e., $60.01 \%$ of the average $19.18 \%$ ). Additionally, the propensity to work increases monotonically over the first 11 years of both data sets, followed by slight fluctuations over the last five years.

Tables 2 and 3, which respectively show one-year transition rates for the whole sample and for the sickness subsample, reveal substantial state persistence and substantial dependence on health status. The row percentages describe the transition percentages from a state at age $t-1$ to a state at age $t$, and the column percentages show percentages of each state at $t-1$ given the state at age $t$. State persistence is revealed in the tables 2 and 3 . A large majority of the individuals who enrolled in school in the last year will enroll currently; however, over $73 \%$ of the whole sample and less than $60 \%$ of sickness subsample will make such a decision. Similarly, the majority of individuals who worked or remained home last year will work or stay at home this year. However, those in the full sample have a larger probability to continue working and a smaller probability staying at home than those in the sickness subsample, showing the importance of health status in determining activity choices. 


\subsection{Passing or failing grades}

The NLSY79 collected the information from the high school transcripts during 1980, 1981, and 1983 for those respondents who were 17 years of age or older, and who were expected to complete high school in the United States. For each person in the sample, the transcript data gathered up to 64 courses that include the grade level at which the course was taken, a code for high school courses, and a grade for each course based on a zero to 4.0 scale, corresponding to grade $F$ to grade $A$. A course is classified as failure if the grade is $F$. An individual is assumed to fail a grade if and only if the individual failed over a half of the courses taken in that grade. This assumption implies that each course is equally important for assessing the progress in school.

Table 4 shows the percentages of failing in high school by grade for the whole sample and for the sickness subsample. In both samples, the probability of failing a grade declines as the grade level becomes higher, from $13.9 \%$ in grade 9 to $3.63 \%$ in grade 12 for the full sample, and from $20.7 \%$ in grade 9 to $7.61 \%$ in grade 12 for the sickness subsample. The declining trend in grade failures may reflect the fact that some students dropped out of school before graduation because of bad grades, health problems, or both. More importantly, table 4 shows that an individual's health status significantly incluences his study outcomes. The possibility of failing a grade for the individuals who had been sick is more than twice than the average of the whole sample, except for the grade 9 in which the failing probability is about 1.5 times higher.

\subsection{Wage and asset}

The real wages used in this analysis are based on a 1984 price level. The average wage in the whole sample is $\$ 20,752$, with a standard deviation of $\$ 47,535$, while the average wage in the sickness subsample is $\$ 18,731$, with a standard deviation of $\$ 11,367$. Being sick reduces an individual's wage by about $10 \%$.

Beginning in 1985, the NLSY79 launched a much larger wealth section. Up to 20 questions about a variety of asset and debt holdings were asked at each subsequent interview, except for $1991 .^{13}$ The asset items used in this analysis include (i) residential property, (ii) cash savings, stock and bond portfolio, etc., (iii) real estate, assets in the

13 The wealth questions were eliminated in 1991 because of budgetary restrictions. 
business, and farm operation, (iv) automobile, (v) mortgage debt, property debt, and other accumulated debt, (vi) other assets each individually worth more than $\$ 500$, and (vii) other debts over $\$ 500$. Together these variables are used to construct the net worth of the assets of each respondent. Since the asset data are collected at the household level, an individual's asset is half of his household asset if he is currently married and his spouse is listed on the household enumeration.

Tables 5 and 6 show the asset distribution by age for the whole sample and the sickness subsample, respectively. The earliest age with reported assets is 21 , because the asset data were not collected until 1985. Given the small size of the observations and possible measurement errors, outlier asset levels are deleted from the sample. ${ }^{14}$ As shown in the tables, both mean and median net assets in the sickness subsample are smaller than those in the whole sample, reflecting the substantial influence of sickness on the accumulation of assets. The prevalent dependence of assets on health is also verified by the proportions of the negative net assets, which are higher in the sickness subsample from ages 22 to 31. In addition, tables 5 and 6 indicate that assets increase with age. Between the ages of 21 and 31, the mean net assets increase by 4.13 for the whole sample and 2.90 times for the sickness subsample, while the median net assets increase by 3.75 times for the whole sample and 3.63 times for the sickness subsample. Moreover, the median net assets are, on average, less than half of the mean levels, reflecting the positively skewed nature of the asset distribution.

\subsection{Skill types}

The model in Section 2 introduces skill endowments for studying and for working. In particular, equation (6) introduces the unobserved study type that affects probability passing or failing a grade, and equation (7) introduces the unobserved market skill type that affects wages. The endowment skills at age 16 are assumed to be unobserved to the econometricians, however, the population proportions of skill types are known. ${ }^{15}$ Denote

\footnotetext{
${ }^{14}$ In total, 107 extremely large and small net asset observations are deleted from the whole sample, while 34 from the sickness subsample.

${ }^{15}$ Keane and Wolpin $(1994,1997)$ undertake the same assumption. Some literatures use the Armed Forces Qualifying Test (AFQT) as a measure of IQ or endowment skill (Neal and Johnson, 1996; Cameron and Heckman, 1998, 1999). This analysis does not adopt AFQT for two reasons. First, AFQT reflects not only an individual's innate endowment but also his parents' and his own
} 
the type portions of high ability for studying and high skill for working as $\mathrm{ro}_{1}$ and $\mathrm{ro}_{2}$, respectively. An individual's skill or study types can be simulated by random draws from the uniform distribution between zero and 1. For example, if an individual's drawn number of his study type is less than $\mathrm{ro}_{1}$, the individual is labeled as having high academic ability; otherwise the individual is labeled as having low academic ability. At each simulated data $f$, the individual's skill types are generated independently from the random draws.

The process to simulate the unobserved skill types suggests that both (6) and (7) with unobserved skills are regime switching models of Hamilton (1989). Consider equation (6) in which there are two regimes: a high-study-type regime and a low-study-type regime. If an individual's latent academic performance $\Phi_{t}^{*}$ belongs to the high-study-type regime, the intercept term in the model is $\xi_{01}$. Otherwise, the intercept term is $\xi_{02}$. Since the model assumes that $\xi_{01}>\xi_{02}$, the two regimes have two distributions that differ in their means. For any individual, the probability that his $\Phi_{t}^{*}$ is drawn from the high-study-type regime is $r o_{1}$. The identification of regime switching models is well established (Hamilton 1989).

\section{Estimation results}

\subsection{Parameter estimates}

The parameter estimates are reported in table 7. The standard deviations are in parentheses, and the total number of parameters is 50 . These parameters are estimated to fit the sequential choices of 15,972 person-period observations, out of which 2,198 had been sick at least once throughout the 16-year period. The choice set at each period consists of decisions on school attendance, job participation, or staying at home, as well as decisions on net asset savings and on health expenditure.

The estimated parameters $\left(\alpha_{0}, \alpha_{1}\right.$, and $\left.\alpha_{2}\right)$ for the mortality rate function (4) show that a healthy individual's mortality is 1.5 percentage points lower than that of the life table. Whether an individual has ever been sick has a very large effect on his mortality rate, while a longer duration of sickness seems to have little additional effect on his mortality 
rate. The mortality rate for an individual who has experienced sickness only at the current age 21 times larger than the life-table mortality and the mortality rate rises to 22 times as large as the life-table mortality if the sickness duration is 3.5 years. As for the survival rate, being sick at age 16 with zero duration of prior sickness decreases the survival rate between age 16 and 30 by $2 \%$, from $98.4 \%$ to $96.4 \%$.

The estimated parameters $\left(\xi_{01}, \xi_{02}, \xi_{1}\right.$, and $\left.\xi_{2}\right)$ of passing or failing a grade in (6) indicate that health and academic skill endowment have a significant effect on an individual's academic success. Among the individuals with high academic ability who account for $86.5 \%$ of the population, the probability that a healthy individual passes a grade is $97.6 \%$. In comparison, a sick individual's probability of passing a grade is $91.2 \%$ if his duration of prior sickness is zero, or $90.88 \%$ if his duration of prior sickness is three years. On the contrary, of the individuals with low academic ability, the probability of passing a grade is $75.4 \%$ if he is healthy, and $53.3 \%$ if he is sick with zero duration. In terms of determining whether an individual passes a grade, health plays a more important role for an individual of low academic ability than for an individual of high academic skill. Specifically, the passing probability of an individual with high academic skill will decrease by $6.4 \%$ as a consequence of sickness, whereas the probability of failure with low academic skill will decrease by $22.8 \%$.

The estimates for parameters in wage equation (7) reveal that sickness reduces wages by $16 \%\left(\gamma_{5}\right)$, which is consistent with some estimates in the literature. ${ }^{16}$ In addition, individuals with high working skill (approximately 59\% of the population) earn about $30 \%$ more than low working type individuals if other characteristics are the same (difference between $\gamma_{01}$ and $\gamma_{02}$ ). Furthermore, the estimates regarding the job adjusting cost, the returns for education and experience are quite reasonable: the absence of work in the last period decreases wages by $13 \%\left(\gamma_{7}\right)$; and an additional year of education increases wages by $10 \%\left(\gamma_{1}\right)$; an additional year of experience increases wages by $10.9 \%$ $\left(\gamma_{2}\right)$ in the first year, and $10.1 \%$ in the second year, and 9.3\% in the third year of experiences, etc..

With respect to the home production function in (8), estimated parameters show that

${ }^{16}$ Empirical estimates on effect of health on wages vary widely, in which Berkovec and Stern (1991) estimate that poor health status reduce wage by $16.7 \%$. See Currie and Madrian (1999) for an extensive review. 
sickness reduces the home production by $\$ 2,716\left(\varphi_{1}\right)$, and an additional year of sickness duration reduces the home production by $\$ 368\left(\varphi_{2}\right)$. The average home production for a healthy individual is $\$ 9,689(\bar{e})$. In addition, wage shock $\varepsilon_{t}^{w}$ and home production shock $\varepsilon_{t}^{e}$ are negatively correlated with the correlation coefficient -0.3816 .

Table 8 reports the probabilities of being sick by health expenditures and by health statuses at ages 16, 25, and 30. As the table shows, both health expenditure and health status have significant effects on the possibility of sickness. If the health expenditure is zero, a healthy individual has about a 50\% chance of getting sick, while a sick individual has more than an $87 \%$ chance of getting sick. The elasticity of health expenditure with respect to the probability of sickness also differs between healthy people and sick people. For example, at age 16, a $\$ 500$ health expenditure reduces a healthy individual's probability of sickness by $81 \%$, from $48 \%$ to $9 \%$. However, a $\$ 500$ health expenditure only reduces the probability of being sick by $36 \%$, from $49 \%$ and $31 \%$. These results indicate that health expenditures have much larger effects in reducing sick probabilities for healthy people than for sick people. Table 8 also illustrates the effect of age on the probability of sickness. As people are older, the effect of health expenditure drops slightly; for example, at age 30, with a $\$ 500$ health expenditure, an individual's probability of sickness is reduced $78 \%$ if healthy and $44 \%$ if sick.

To evaluate the effect of education on health, we calculate the probability of sickness when education attainments are 8,12 , and 16 , which represent the education level of pre-high school, high school graduate, and four-year college graduate. Table 9 shows that education has a positive effect on the probability of sickness, especially for sick individuals, although the effect is much less significant than health expenditure and health status. Specifically, if there is no health expenditure, the probability of sickness for a 20 -year-old and healthy individual who has 8 years of education is $51 \%$. When his education is 12 and 16 years, the corresponding probabilities of sickness drop to $48 \%$ and $45 \%$, respectively.

Finally, the coefficient of relative risk aversion is 0.8043 and the preference discount factor 0.9795, which are consistent with some estimates in the literature (see, for example, Gan, Gong, Hurd, and McFadden 2004). The estimated cost of education beyond high school is $\$ 4,328$ per year, and the net income boundary is $-\$ 585$, below which the health 
expenditure is zero.

\subsection{Within-sample fit}

With the estimated parameters, the validation of the model can be tested by the within-sample fit. Based on a simulation of 8,000 individuals, table 10 compares the predicted and actual values of selected state variables by the whole sample and by the sickness subsample. As can be seen, the model accurately matches the mean level of completed schooling years in the whole sample. However, at a more disaggregated level, the predicted means differ from the observed means. For example, the model overstates the proportion of those who have completed 12 years of schooling (high school) and understates the proportion of those who have completed 16 years of schooling (college). In the sickness subsample, the model predicts a slightly higher mean level of schooling years and overstates the proportion of those who have completed 12 years of schooling.

The model fits the proportions of those who choose to work, to go to school, and to stay at home quite well, except that it overstates the proportion of school attendance in the sickness subsample and understates the proportion of working in the whole sample. A further fit comparison of the predicted and actual school attendance, working and home decisions by age for the whole sample and for the sickness subsample is illustrated in figures 3a and 3b.

In terms of the probabilities of failing a grade (table 10), the model correctly predict that health has a large effect on the probabilities. However, the predicted probabilities have less variation than observed probabilities across grade levels. With respect to the asset fit, the model captures the broadly increasing pattern with age. Figures 4a and 4b display the predicted and actual mean assets by age. It is clear that the model does better in predicting asset levels for the whole sample than for the sickness subsample.

As predicted by the model, the mean health expenditure in the sickness data is $5.4 \%$ larger than in the full sample. This is because sick individuals have to spend more on health to reduce the chance of being sick in succeeding years, while healthy individuals can spend smaller amounts on health and still maintain a relatively low probability of sickness. Figure 5 shows the predicted and actual percentages of sick individuals from the simulated data and from the observed full sample. The percentages of people who are 
sick in both samples range from $4.1 \%$ to $5.2 \%$. The largest and smallest gaps between predicted and actual sick percentages are $0.29 \%$ at age 30 and $0.02 \%$ at age 27 , respectively. Moreover, the age pattern of health expenditure and the percentage of zero health expenditure are portrayed in figure 6. It is shown that the mean health expenditure increases by age, from $\$ 783$ at age 16 to $\$ 952$ at age 31, an average increase of 1.34\% per year. Concurrently, the ratio of zero health expenditure increases from zero in the first four years (i.e., ages 16 to 19 ) to $0.94 \%$ at age 30 . Note that according to the model's assumption, as the individual's net income falls lower than the boundary of $-\$ 549$, his health expenditure is zero. The increase in the trend of the percentage of zero health expenditure implies the dispersion of assets and earnings.

\subsection{Initial health status and education effects}

As has been observed, an individual's initial characteristics have a significant effect on his future behavior of alternative choices, which will subsequently determine his health, educational attainment and wealth. It is interesting to investigate how the education, health and welfare are related to initial levels of completed education and health status at the age of 16 .

Table 11 reports the simulation results of initial health status effects on selected variables, conditional upon initial schooling. Approximately 5\% of individuals completed ten years or more schooling by age 16 in the observation sample. As seen in the table, initial health status is an important determinant of education, survival probability, assets, health expenditure, and lifetime welfare. Moreover, the effects of initial health limitations are more substantial for individuals with lower levels of education than for individuals with higher levels of education. For instance, illness at age 16, on average, decreases the average level of education at age 30 by 0.35 year for individuals with initial schooling of nine years or less, whereas it decreases by 0.27 year for individuals with initial schooling of ten years or more. Moreover, the decrease in the probability of survival at age 30, resulting from the illness at age 16 , is $2.8 \%$ for those with low initial education, compared to $1 \%$ for those with higher levels of education. Finally, due to the health limitation at age 16 , the mean present value of lifetime utility decreases $13 \%$ for the individuals with low initial education and $11 \%$ for those with high initial education, 
respectively.

In order to study the effect of initial education, the simulated sample is divided into two groups. One group consists of observations who have 10 or more years of education at age 16, the rest of the observations is in another group. Table 11 reports the results. It indicates that initial education also has a significant effect on the selected variables. If an individual has 10 or more years of education at age 16, he would have 1.44 more years of education when he reaches age 30 .

It is important to notice that we cannot conclude whether the initial condition of health is more important than that of education because of different measure in education and in health. Next we consider a policy simulation in which we can compare relative importance between education and health.

\subsection{Policy application}

In this section, we conduct two policy experiments. The first experiment is a direct college tuition subsidy, and the second is a health expenditure subsidy during high school. The two experiments will incur the same amount of per capita cost. Therefore, by comparing the outcomes of the two experiments, we are able to evaluate relative difference in effectiveness between subsidizing health and subsidizing education. For each subsidy, we simulate a sample of 8,000 individuals. The results for both policy simulations are discussed below.

\subsubsection{College tuition subsidy}

Table 12 reports the distribution effect of a \$2,100 per year college tuition subsidy, which is about $50 \%$ of the estimated cost of college education (estimated $e c=\$ 4,328$ ). Although the subsidy is limited to college students, it will also affect the individuals' decisions before entering college because they anticipate it before making their decision to enter college. The simulated sample is divided into two subsamples: those who have been sick at least once before age 21 (12.2\% of the population before the subsidy) and those who have remained healthy before age 21 ( $87.8 \%$ of the population before the subsidy). Also, people are classified by their endowment types based on the estimated parameters of population type ratio: high ability in both school and work (group 1), high 
ability in school and low ability in work (group 2), low ability in school and high ability in work (group 3), and low ability in both school and work (group 4). For convenience, the baseline results without subsidy are listed.

As expected, the college tuition subsidy increases the levels of state variables, including educational attainment, years in college, assets, and present value of lifetime utility. Among the 8,000 simulated individuals, the average highest schooling years completed increases by 0.42 years, from 13.39 to 13.81 years; and the mean years in college increase by 0.35 years from 1.85 to 2.20 years. The mean value of assets at age 30 increases $18 \%$, from $\$ 19,134$ to $\$ 22,608$. The mean expected present value of lifetime utility at age 16 increases $10.7 \%$, from 185.6 to 197.4 . Finally, the percentage of those who have ever been sick at least once before age 21 decreases 0.9 percentage points, from $12.2 \%$ to $11.3 \%$.

As seen, the college tuition subsidy has a smaller effect on a sick person than on a healthy person. In particular, educational attainment changes little for simulated individuals who are in groups 3 and 4, and who have experienced at least one bout of sickness before age 21. Specifically, the private gain of welfare from the subsidy is smaller for the sick person than for the healthy person. The mean present value of lifetime utility increases $5.6 \%$ for people in the sickness subsample, compared to $11 \%$ for healthy people.

In this experiment, not all simulated individuals will attend colleges. For those who ever attend colleges, their average gains are \$4,620, while for those who never attend colleges, their gains are zero from the program. Therefore, the per capita cost of a college tuition subsidy is $\$ 2,247$, if shared by all of the individuals. In addition, the gains are very different across groups and health statuses. Overall, observations in groups 1 and 2 experience greater gains from the program because they have significantly large college attendance regardless of the subsidy. In addition, healthy people gain more than sick people.

\subsubsection{High school health expenditure subsidy}

Table 13 explores the effect of a $\$ 778$ per year health expenditure subsidy per year for high school students. The per capita cost of the program is $\$ 2,247$, which is the same 
amount as the per capita college tuition subsidy. This amount is smaller than the cost of subsidizing everybody at $\$ 778$ for four years starting at age 16 since some simulated individuals will choose to work or to stay at home and will not get the health expenditure subsidy.

As shown, the average highest year of schooling completed increases by 0.53 , which is 0.11 year more than with the college tuition subsidy. The mean years spent in college increases by 0.44 , a little larger than with the college tuition subsidy. In addition, the mean assets at age 30 are almost the same as in the case of the college tuition subsidy. The overall welfare has a tiny increase with respect to the college tuition subsidy program.

The gain distribution is much different in this case. Gains of sick and low endowment people improve substantially. This could be explained by the two reasons. First, health limitation decreases the possibility of passing a grade, and graduating from high school is the only path assumed in this paper to attending college. Hence, a college tuition subsidy is not as attractive to those who anticipate a small probability of passing a grade. However, a high school health expenditure provides a direct channel for this population to gain from the subsidy. Second, for those people who would go to college even without the tuition subsidy, the benefits are greatest because of the level effect of the subsidy. But, for those who are induced to attend college, the benefits incurred from the marginal effect, i.e., the marginal indifference between college attendance and other options.

\section{Conclusion}

In this paper we structurally estimate a dynamic model on activity choices of schooling, work, or staying at home, on health expenditure, and on levels of saving over the life cycle using 16 years of data from the NLSY79. The structural framework explicitly models two existing theoretical hypotheses on the correlation between health and education. The model is estimated using the recently developed generalized indirect inference.

The model's estimates support that health and education are interdependent since all coefficients that correspond to the two alternative hypotheses are statistically significant. In particular, the estimation results imply that an individual's education, health 
expenditure, and prior health status influence his health status. Meanwhile, an unhealthy individual has a lower probability of passing a grade, a higher mortality rate, and a lower wage. Indeed, health plays an extremely important role in determining an individual's educational attainment. On average, having been sick before the age of 21 decreases the educational attainment by 1.4 years. Policy experiments based on the model's estimates indicate that a health expenditure subsidy conditional on high school attendance would have a larger impact on educational attainment than a direct college tuition subsidy. In particular, a direct college tuition subsidy will favor healthy individuals, especially those who are healthy and have low academic ability, while a high school health expenditure subsidy will favor sick individuals, especially those who are sick and have high academic ability. 


\section{Appendix: Forms of Descriptive Statistical Models}

As discussed in Section 2.3.1, the descriptive statistical model at time $t$ is a linear model, given in (16). The construction of $\left\{y_{t}, x_{t}\right\}$ in (16) is described below.

(1) $t=1$, i.e., age 16

The regressors include a constant term, schooling years, indicator of sickness, and duration of sickness:

$$
x_{1}=\left(1, s c h_{1}, D_{1}, s l_{1}\right) .
$$

Note that because of the data limitation in calculating the effective schooling years $e d u$, we use the observed schooling years $s c h$. The indicator for success in school is chosen as an independent variable.

The set of dependent variables consists of the dummies for working and for schooling, wage, indicators of passing the grade, and the dummy for sickness at $t=2$ (age 17). Some of the dependent variables are allowed to be missing. If for some individuals, one or more variables were missing or unobserved, then the corresponding dependent variables are accordingly missing from these individuals at this age. For example, if the transcript data were missing or unobserved for individual $i$ (an unobserved transcript may occur because he was in middle school or college during the time of survey), then the dependent variable of the indicator of the passing the grade will not be included for this individual. The set of the dependent variables for the observed data is:

$$
\left.y_{1}=\left(d_{1,1}^{1}, w_{1}, d_{2,1}^{1} \text {, pass(if in high school }\right), D_{2}\right) .
$$

The simulated data consists of the same individuals as in observed data, except that the simulated discrete variables are replaced by the smooth functions discussed in Section 2. That is to say that the number of linear regression equations for simulated data and observed data is equal.

(2) $1<t<6$, i.e., from age 17 to 20

For $t=3,4$, or 5 , the regressors include a constant term, schooling years, working experiences, dummies for work and for school attendance, indicator of sickness, and duration of sickness: 


$$
x_{t}=\left(1, s c h_{t}, e p_{t}, d_{1, t}^{1}, d_{2, t}^{1}, D_{t}, s l_{t}\right) .
$$

The independent variables for $t=2$ are different from those for $t=3,4$ or 5 , in which working experience was not included because at this period $e p_{2}$ is equal to $d_{1,1}^{1}$ (remember that the initial working experience is set at zero):

$$
x_{2}=\left(1, s c h_{2}, d_{1,1}^{1}, d_{2,1}^{1}, D_{2}, s l_{2}\right) \text {. }
$$

The dependent variables are:

$$
y_{t}=\left(d_{1, t}^{1}, w_{t}, d_{2, t}^{1}, \operatorname{pass}(\text { if in high school }), D_{t}\right) .
$$

Similar to the case of $t=1$, if some observed variables were missing or unobserved, the corresponding dependent variables are also missing.

(3) $t=6$, i.e., age 21 .

At this age, some agents start to have asset data and some do not. The set of the independent variables are the same as in (A.3.1). The set of dependent variables is:

$$
y_{6}=\left(d_{1,6}^{1}, w_{6}, d_{2,6}^{1}, \operatorname{pass}(\text { if in high school }), D_{7}, A_{6}\right) \text {. }
$$

(4) $6<t<16$, i.e., from age 22 to 30

It is necessary to have two descriptive statistical models because of the asset data. Both models have the same set of dependent variables:

$$
y_{t}=\left(d_{1, t}^{1}, w_{t}, d_{2, t}^{1}, D_{t+1}, A_{t}\right) \text {. }
$$

Note that the indicator for passing the grade is not included in (A.6) because of the convenient assumption that individuals should have finished their high school by age 22 . Actually, in the sample, only 5 individuals who were over 21 years old were still in high school.

The first descriptive statistical model includes all the individuals whose assets at $t-1$ were missing or unobserved. In contrast, the second model includes all the individuals whose assets at $t-1$ were observed. The set of independent variables for the first model is the same as in (A.3.1), while for the second one it is:

$$
x_{t}=\left(1, s c h_{t}, e p_{t}, d_{1, t-1}^{1}, d_{2, t-1}^{1}, D_{t}, s l_{t}, A_{t-1}\right) \text {. }
$$


(5) $t=16$, i.e., age 32

The descriptive statistical models are similar to the case of $6<t<16$, in which the models are distinguished by whether the assets at period 15 were observed. The set of independent variables for the first model is:

$$
x_{16}=\left(1, s c h_{16}, e p_{16}, d_{1,15}^{1}, d_{2,15}^{1}, D_{16}, s l_{16}\right),
$$

\section{(A.8.1)}

and for the second model is:

$$
x_{16}=\left(1, s c h_{16}, e p_{16}, d_{1,15}^{1}, d_{2,15}^{1}, D_{16}, s l_{16}, A_{15}\right) .
$$

Because the sample does not contain the information for health at $t=17$, the set of dependent variables is:

$$
y_{16}=\left(d_{1,16}^{1}, w_{16}, d_{2,16}^{1}, A_{16}\right) .
$$




\section{References}

Berkovec, J. and S. Stern. (1991), “Job Exit Behavior of Older Men,” Econometrica 59: 189-210.

Cameron, Steven, and James J. Heckman (1993), “The Nonequivalence of High School Equivalents,” Journal of Labor Economics 11: 1-47.

Cameron, Steven, and James J. Heckman (1998), “The Dynamics of Educational Attainment for Blacks, Hispanics, and Whites,” Department of Economics, University of Chicago, unpublished paper.

Currie, Janet, and R. Hyson, (1999), "Is the Impact of Health Shocks Cushioned by Socioeconomic Status? The Case of Low Birth Weight," American Economic Review 89: 245-250.

Currie, Janet, and Brigitte Madrian, (1999), "Health, Health Insurance and the Labor Market.” In Ashenfelter and Card, eds, Handbook of Labor Economics. Vol 3. Elsevier Sciences.

Fuchs, V. R. (1982), “Time Preferences and Health: An Exploratory Study,” in V. R. Fuchs, ed., Economic Aspects of Health (Chicago: University of Chicago Press for the National Bureau of Economic Research): 93-120.

Gan, Li and Guan Gong (2004), “Mortality Risk and Educational Attainment of Black and White Men.” National Bureau of Economic Research Working Paper, \#10381.

Gan, Li, Guan Gong, Michael Hurd, and Daniel McFadden (204), “Subjective Mortality Risks and Bequests.” National Bureau of Economic Research Working Paper, \#10789.

Gourieroux, C., A. Monfort, and E. Renault (1993), “Indirect Inference,” Journal of Applied Econometrics 8: S85-S118.

Grossman, Michael (1972), “On the Concept of Health Capital and the Demand for Health,” Journal of Political Economy 80: 223-255.

Grossman, Michael (1975), "The Correlation between Health and Schooling,” in N. E. Terleckyj, ed., Household Production and Consumption (New Y ork: Columbia University Press for the National Bureau of Economic Research): 147-211.

Grossman, Michael (1999), “The Human Capital Model of the Demand for Health,” National Bureau of Economic Research Working Paper: 7078.

Grossman, Michael, and R. Kaestner (1997), "Effects of Education on Health,” in J. R. Berhman and N. Stacey, eds. The Social Benefits of Education (Ann Arbor: University of Michigan Press).

Hamilton, James (1989), "A New Approach to the Economic Analysis of Nonstationary Time Series and the Business Cycle.” Econometrica 57(2): 357-384.

Keane, Michael P., and K. Wolpin (1994), "The Solution and Estimation of Discrete Choice Dynamic Programming Models by Simulation and Interpolation: Monte Carlo Evidence,” Review of Economics and Statistics 76: 648-72. 
Keane, Michael P., and K. Wolpin (1997), “The Career Decisions of Young Men,” Journal of Political Economy 105: 473-522.

Keane, Michael P., and Anthony A. Smith (2003), "Generalized Indirect Inference for Discrete Choice Models.” Department of Economics, Yale University, working paper.

Kenkel, Donald S. (1991), "Health Behavior, Health Knowledge, and Schooling," Journal of Political Economy 99: 287-305.

Kenkel, Donald S. (2000), "Prevention,” in Handbook of Health Economics., volume 1B. (North-Holland: Elsevier Science): 1675-1720.

Levy, Helen, and David Meltzer (2001), "What Do We Really Know About Whether Health Insurance Affects Health?” University of Chicago Harris School of Public Policy, unpublished working paper.

Neal, Derek A., and William R. Johnson (1996), "The Role of Premarket Factors in Black-White Wage Differences," Journal of Political Economy 104: 869-95.

Newhouse, Joseph P. (1993), Free for All? Lessons from the RAND Health Insurance Experiment. Cambridge and London: Harvard University Press.

Perri, Timothy J. (1984), "Health Status and Schooling Decisions of Young Men,” Economics of Education Review:

Rosenzweig, M. R. and Schultz, T. P. (1991), "Education and Household Production of Child Health," in Proceedings of the American Statistical Association (Social Statistics Section) (Washington, DC: American Statistical Association). 
Table 1: Percentage of People Choosing School, Work, and Home

\begin{tabular}{|c|c|c|c|c|c|c|c|c|}
\hline \multirow[b]{2}{*}{ Age } & \multicolumn{4}{|c|}{ Sickness Subsample } & \multicolumn{4}{|c|}{ Full Sample } \\
\hline & School & Work & Home & $\overline{\text { TOTAL }}$ & $\overline{\text { School }}$ & Work & Home & $\overline{\text { TOTAL }}$ \\
\hline \multirow[t]{2}{*}{16} & 81.82 & 9.09 & 9.09 & 100 & 87.38 & 6.59 & 6.03 & 100 \\
\hline & (36) & (4) & (4) & (44) & (928) & (70) & (64) & (1062) \\
\hline \multirow[t]{2}{*}{17} & 69.87 & 14.29 & 15.87 & 100 & 78.42 & 11.02 & 10.56 & 100 \\
\hline & (44) & (9) & (10) & (63) & (832) & $(117)$ & $(112)$ & (1061) \\
\hline \multirow[t]{2}{*}{18} & 38.55 & 28.92 & 32.53 & 100 & 49.95 & 27.57 & 22.47 & 100 \\
\hline & (32) & (24) & $(27)$ & (83) & (529) & (292) & (238) & (1059) \\
\hline \multirow[t]{2}{*}{19} & 31.96 & 27.84 & 40.21 & 100 & 41.12 & 33.46 & 25.43 & 100 \\
\hline & (31) & $(27)$ & (39) & (97) & (435) & (354) & (269) & (1058) \\
\hline \multirow[t]{2}{*}{20} & 22.32 & 29.46 & 48.22 & 100 & 31.63 & 39.68 & 28.69 & 100 \\
\hline & (25) & (33) & (54) & (112) & (334) & (419) & (303) & (1056) \\
\hline \multirow[t]{2}{*}{21} & 17.05 & 34.11 & 48.84 & 100 & 28.53 & 42.65 & 28.82 & 100 \\
\hline & (22) & (44) & (63) & (129) & (301) & $(450)$ & (304) & (1055) \\
\hline \multirow[t]{2}{*}{22} & 11.51 & 46.04 & 42.44 & 100 & 19.18 & 60.59 & 20.23 & 100 \\
\hline & (16) & (64) & (59) & (139) & (202) & (638) & (213) & (1053) \\
\hline \multirow[t]{2}{*}{23} & 10.53 & 50.66 & 38.81 & 100 & 15.5 & 66.54 & 17.97 & 100 \\
\hline & (16) & (77) & (59) & (152) & (163) & $(700)$ & (189) & (1052) \\
\hline \multirow[t]{2}{*}{24} & 6.06 & 52.73 & 41.21 & 100 & 9.64 & 74.14 & 16.22 & 100 \\
\hline & (10) & (87) & (68) & (165) & (101) & (777) & $(170)$ & (1048) \\
\hline \multirow[t]{2}{*}{25} & 3.98 & 56.82 & 39.20 & 100 & 5.63 & 78.63 & 15.74 & 100 \\
\hline & (7) & $(100)$ & (69) & (176) & (59) & (824) & (165) & (1048) \\
\hline \multirow[t]{2}{*}{26} & 3.30 & 60.44 & 36.26 & 100 & 4.3 & 80.88 & 14.82 & 100 \\
\hline & (6) & $(110)$ & (66) & (182) & (45) & (846) & (155) & (1046) \\
\hline \multirow[t]{2}{*}{27} & 2.63 & 58.95 & 38.42 & 100 & 3.25 & 79.43 & 17.32 & 100 \\
\hline & (5) & (112) & (73) & (190) & (34) & (830) & (181) & (1045) \\
\hline \multirow[t]{2}{*}{28} & 1.96 & 52.45 & 45.59 & 100 & 2.87 & 73.97 & 23.16 & 100 \\
\hline & (4) & (107) & (93) & (204) & (30) & (773) & (242) & (1045) \\
\hline \multirow[t]{2}{*}{29} & 1.86 & 53.02 & 45.12 & 100 & 2.68 & 72.15 & 25.17 & 100 \\
\hline & (4) & $(114)$ & (97) & (215) & (28) & (754) & (263) & (1045) \\
\hline \multirow[t]{2}{*}{30} & 1.24 & 52.80 & 45.96 & 100 & 2.19 & 69.33 & 28.48 & 100 \\
\hline & (2) & (85) & (74) & (161) & (17) & (538) & (221) & (776) \\
\hline \multirow[t]{2}{*}{31} & 1.16 & 51.16 & 47.68 & 100 & 1.94 & 68.47 & 29.59 & 100 \\
\hline & (1) & $(44)$ & (41) & (86) & (9) & (317) & (137) & (463) \\
\hline \multirow[t]{2}{*}{ TOTAI } & 11.56 & 42.81 & 45.63 & 100 & 25.34 & 54.46 & 20.20 & 100 \\
\hline & (254) & $(941)$ & $(1,003)$ & $(2,198)$ & $(4,047)$ & $(8,699)$ & $(3,226)$ & $(15,972)$ \\
\hline
\end{tabular}

Note: Number of observations is in parenthesis.

Sickness subsample at age $t$ consists of individuals who have been sick at least once up to and including age $t$. 
Table 2: Transition Matrix between two States

(Full sample: White Males Aged 16-31*)

\begin{tabular}{|c|c|c|c|}
\hline \multirow[b]{2}{*}{ Choice $(t-1)$} & \multicolumn{3}{|c|}{ Choice $(t)$} \\
\hline & School & Work & Home \\
\hline \multicolumn{4}{|l|}{ School: } \\
\hline Row \% & 73.49 & 12.98 & 13.52 \\
\hline Column \% & 92.59 & 9.25 & 17.61 \\
\hline \multicolumn{4}{|l|}{ Work: } \\
\hline Row \% & 2.31 & 86.98 & 10.7 \\
\hline Column \% & 3.71 & 78.97 & 17.77 \\
\hline \multicolumn{4}{|l|}{ Home: } \\
\hline Row \% & 4.26 & 23.92 & 71.82 \\
\hline Column \% & 3.7 & 11.78 & 64.62 \\
\hline
\end{tabular}

* Number of observations: 14,910 .

Table 3: Transition Matrix between Two States (Sickness Subsample: White Males Aged 16-31*)

\begin{tabular}{lrlll}
\hline \hline \multirow{2}{*}{ Choice $(t-1)$} & \multicolumn{3}{l}{ Choice $(t)$} \\
\cline { 3 - 5 } School: & School & Work & Home \\
\cline { 3 - 5 } & Row \% & 58.7 & 15.38 & 25.97 \\
Work & Column \% & 83.09 & 6.25 & 10.66 \\
& Row \% & 1.81 & 82.3 & 15.89 \\
Home & Column \% & 5.95 & 77.9 & 16.15 \\
& Row \% & 3.49 & 19.25 & 77.26 \\
\multicolumn{2}{c}{ Column \% } & 11.22 & 16.72 & 72.05 \\
\hline
\end{tabular}

* Number of observations: 2,154. 
TABLE 4: Percentage Failing Grades 9, 10, 11, and 12 * White Males Aged 16-31

\begin{tabular}{lcccc}
\hline \hline Grade & $\mathbf{9}$ & $\mathbf{1 0}$ & $\mathbf{1 1}$ & $\mathbf{1 2}$ \\
\hline Full Sample & 13.9 & 6.08 & 5.54 & 3.63 \\
& $(374)$ & $(954)$ & $(903)$ & $(799)$ \\
Sickness Subsample & 20.69 & 20.93 & 19.57 & 7.61 \\
& $(35)$ & $(72)$ & $(71)$ & $(67)$ \\
\hline
\end{tabular}

* Number of observations with transcripts report are in parentheses.

Table 5: Asset Distribution

Full Sample: White Males Aged 21 - 31

\begin{tabular}{|c|c|c|c|c|c|c|c|}
\hline Age & Median & Mean & Std & Max & Min & $\begin{array}{l}\text { No. } \\
\text { Obs. }\end{array}$ & $\begin{array}{l}\text { Percent } \\
\text { Negative }\end{array}$ \\
\hline 21 & 1,931 & 4,209 & 6,404 & 55,330 & $-15,296$ & 230 & 9.8 \\
\hline 22 & 2,248 & 5,019 & 8,262 & 80,524 & $-14,753$ & 497 & 11.2 \\
\hline 23 & 2,752 & 5,883 & 10,581 & 115,630 & $-12,703$ & 921 & 16.4 \\
\hline 24 & 2,863 & 6,263 & 12,507 & 176,972 & $-31,618$ & 911 & 16.7 \\
\hline 25 & 3,590 & 8,082 & 16,071 & 196,907 & $-36,624$ & 907 & 15.3 \\
\hline 26 & 4,003 & 9,833 & 20,235 & 209,874 & $-43,152$ & 938 & 16.6 \\
\hline 27 & 5,237 & 12,803 & 22,458 & 227,072 & $-43,722$ & 677 & 16.7 \\
\hline 28 & 5,565 & 14,294 & 26,456 & 247,706 & $-33,388$ & 607 & 15.0 \\
\hline 29 & 7,443 & 15,424 & 27,621 & 262,705 & $-37,028$ & 438 & 12.9 \\
\hline 30 & 8,628 & 18,501 & 35,369 & 298,728 & $-21,211$ & 589 & 11.6 \\
\hline 31 & 9,168 & 21,599 & 48,360 & 338,994 & $-24,756$ & 351 & 10.7 \\
\hline
\end{tabular}

Note: In 1984 dollars. 
TABLE 6: Asset Distribution

Sickness Data: White Males Aged 21 - 31

\begin{tabular}{|c|c|c|c|c|c|c|c|}
\hline Age & Median & Mean & Std & Max & Min & $\begin{array}{l}\text { No. } \\
\text { Obs. }\end{array}$ & $\begin{array}{l}\text { Percent } \\
\text { Negative }\end{array}$ \\
\hline 21 & 1,333 & 3,389 & 6,306 & 16,927 & $-8,035$ & 29 & 6.7 \\
\hline 22 & 2,058 & 2,737 & 4,091 & 19,434 & $-7,402$ & 67 & 20.9 \\
\hline 23 & 2,566 & 5,064 & 8,042 & 36,585 & $-8,714$ & 130 & 17.7 \\
\hline 24 & 2,654 & 5,257 & 10,030 & 61,999 & $-13,719$ & 141 & 17.0 \\
\hline 25 & 3,000 & 6,289 & 9,488 & 52,133 & $-10,518$ & 148 & 17.6 \\
\hline 26 & 3,545 & 7,054 & 12,002 & 62,358 & $-11,312$ & 160 & 20.0 \\
\hline 27 & 4,886 & 10,452 & 17,390 & 93,206 & $-6,415$ & 114 & 18.2 \\
\hline 28 & 3,481 & 8,470 & 14,398 & 69,612 & $-12,197$ & 103 & 18.5 \\
\hline 29 & 3,703 & 9,898 & 15,695 & 84,883 & $-12,583$ & 97 & 17.5 \\
\hline 30 & 5,036 & 11,823 & 18,375 & 77,389 & $-9,347$ & 118 & 16.1 \\
\hline 31 & 6,169 & 13,203 & 23,483 & 96,098 & $-8,479$ & 65 & 12.3 \\
\hline
\end{tabular}

Note: In 1984 dollars.

Sickness data at age $t$ consists of individuals who reported health limitation at least once up to and including age $t$. 
TABLE 7: Estimates of the Model

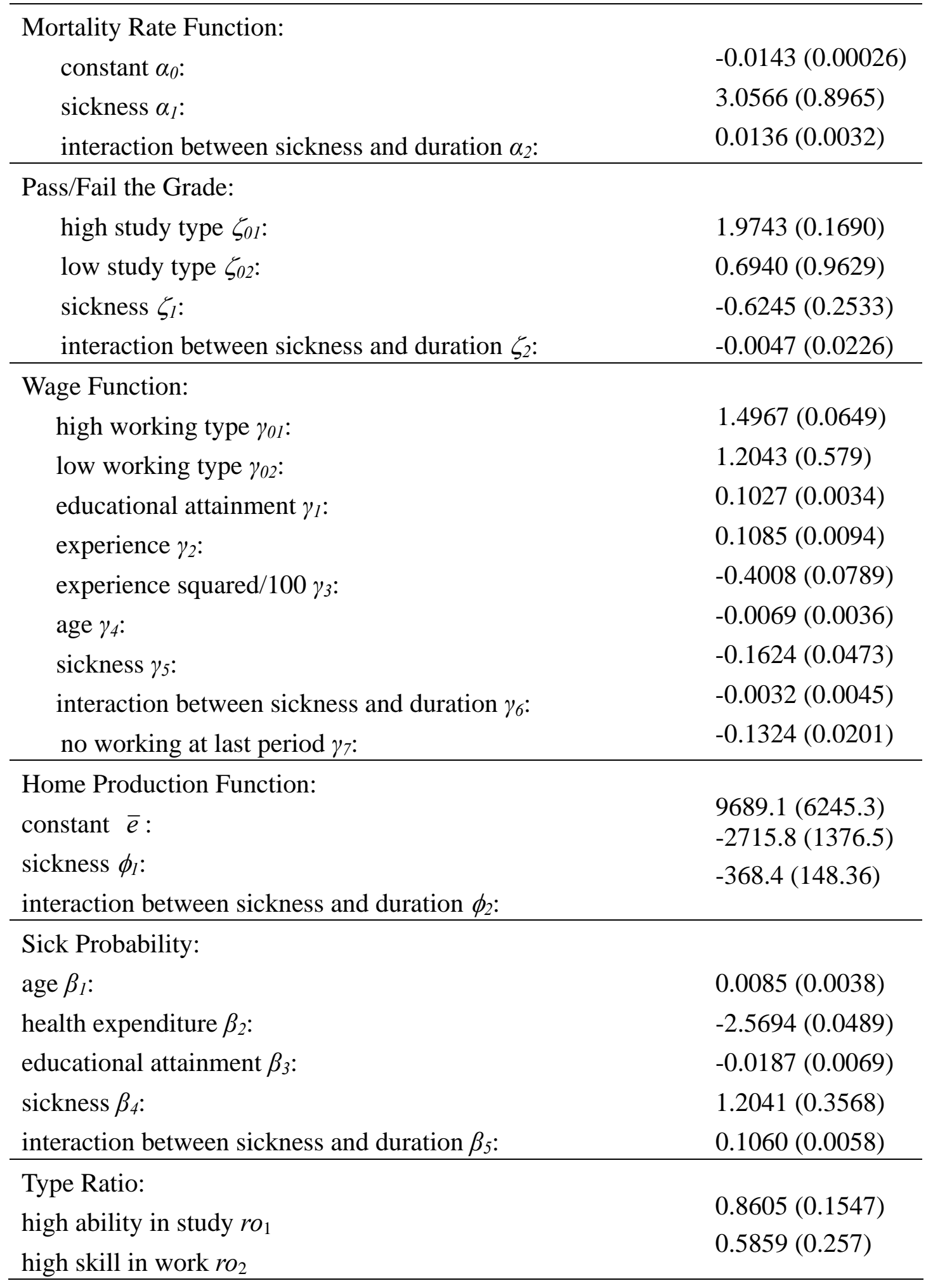


Table 7 Estimates of the Model (Cont.)

\begin{tabular}{|c|c|}
\hline \multicolumn{2}{|l|}{ Terminal Value Function: } \\
\hline constant $\tau_{01}$ : & $6.0259(2.6101)$ \\
\hline high study type $\tau_{02}$ : & $0.1002(0.0258)$ \\
\hline high work type $\tau_{03}$ : & $0.1011(0.0326)$ \\
\hline sickness $\tau_{1}$ : & $-0.547(0.247)$ \\
\hline interaction between sickness and duration $\tau_{2}$ : & $-0.0582(0.0265)$ \\
\hline educational attainment $\tau_{3}$ : & $5.409(2.068)$ \\
\hline educational attainment squared /100 $\tau_{4}$ : & $2.3054(0.216)$ \\
\hline asset $\tau_{5}$ : & $0.1594(0.0231)$ \\
\hline asset squared / $10^{5} \tau_{6}$ : & $-0.000181(0.0025)$ \\
\hline experience $\tau_{7}$ : & $1.1541(0.269)$ \\
\hline experience squared /100 $\tau_{8}:$ & $0.1182(0.146)$ \\
\hline interaction between education and high study type $\tau_{9}$ : & $0.1664(0.589)$ \\
\hline interaction between education and high work type $\tau_{10}$ : & $0.1001(0.0698)$ \\
\hline interaction between asset and high study type $\tau_{11}$ : & $0.001018(0.0263)$ \\
\hline interaction between asset and high work type $\tau_{12}$ : & $0.000602(0.0025)$ \\
\hline interaction between experience and high study type $\tau_{13}$ : & $0.001031(0.006)$ \\
\hline interaction between experience and high work type $\tau_{14}$ : & $0.003028(0.0024)$ \\
\hline \multicolumn{2}{|l|}{ Error: } \\
\hline standard deviation of wage $\sigma_{w}$ : & $0.5137(0.0698)$ \\
\hline standard deviation of home production $\sigma_{e}$ : & $8.1867(3.694)$ \\
\hline correlation $\sigma_{w e}$ : & $-1.6049(0.1895)$ \\
\hline Preference Discount Factor $\delta$ : & $0.9795(0.2793)$ \\
\hline Coefficient of Relative Risk Aversion $\sigma$ : & $0.8043(0.3691)$ \\
\hline Education Cost ec: & $\$ 4328(1569.2)$ \\
\hline Net Income Boundary NIB: & $-\$ 584.8(178.25)$ \\
\hline
\end{tabular}

Note: Standard errors are in parentheses. 
TABLE 8: Estimated Sick Probabilities in Percentage* by Age, Health Expenditure, and Health Status

\begin{tabular}{|c|c|c|c|c|c|c|}
\hline \multirow[b]{2}{*}{ Age } & \multirow[b]{2}{*}{$\begin{array}{c}\text { Health } \\
\text { Expenditure }\end{array}$} & \multirow[b]{2}{*}{ Healthy } & \multicolumn{4}{|c|}{ Sick } \\
\hline & & & $\begin{array}{c}\text { 0-year } \\
\text { duration }\end{array}$ & $\begin{array}{c}\text { 1-year } \\
\text { duration }\end{array}$ & $\begin{array}{c}\text { 3-year } \\
\text { duration }\end{array}$ & $\begin{array}{c}\text { 5-year } \\
\text { duration }\end{array}$ \\
\hline \multirow[t]{6}{*}{16} & 0 & 47.97 & 87.56 & 89.60 & 92.94 & 95.38 \\
\hline & $\$ 250$ & 24.40 & 69.52 & 73.13 & 79.64 & 85.1 \\
\hline & $\$ 500$ & 9.08 & 44.77 & 48.98 & 57.39 & 65.48 \\
\hline & $\$ 750$ & 2.4 & 21.95 & 25.21 & 32.42 & 40.36 \\
\hline & $\$ 1,000$ & 0.44 & 7.83 & 9.50 & 13.6 & 18.77 \\
\hline & $\$ 1,750$ & 0 & 0.04 & 0.06 & 0.12 & 0.25 \\
\hline \multirow[t]{6}{*}{25} & 0 & 51.02 & 89.06 & 90.92 & 93.91 & 96.08 \\
\hline & $\$ 250$ & 26.87 & 72.15 & 75.59 & 81.73 & 86.81 \\
\hline & $\$ 500$ & 10.40 & 47.80 & 52.03 & 60.37 & 68.26 \\
\hline & $\$ 750$ & 2.86 & 24.28 & 27.71 & 35.22 & 43.35 \\
\hline & $\$ 1,000$ & 0.55 & 9.02 & 10.86 & 15.34 & 20.9 \\
\hline & $\$ 1,750$ & 0 & 0.05 & 0.08 & 0.16 & 0.31 \\
\hline \multirow[t]{6}{*}{30} & 0 & 52.71 & 89.83 & 91.59 & 94.41 & 96.42 \\
\hline & $\$ 250$ & 28.29 & 73.56 & 76.91 & 82.84 & 87.69 \\
\hline & $\$ 500$ & 11.19 & 49.50 & 53.72 & 62 & 69.76 \\
\hline & $\$ 750$ & 3.15 & 25.62 & 29.15 & 36.81 & 45.03 \\
\hline & $\$ 1,000$ & 0.62 & 9.73 & 11.68 & 16.37 & 22.15 \\
\hline & $\$ 1,750$ & 0 & 0.06 & 0.09 & 0.18 & 0.35 \\
\hline
\end{tabular}

* Education attainment is 10 grades.

** In 1984 dollars. 
TABLE 9: Estimated Education Effect on Sick Probability

\begin{tabular}{|c|c|c|c|c|}
\hline \multirow[b]{2}{*}{ Grade } & \multirow[b]{2}{*}{$\begin{array}{c}\text { Health } \\
\text { Expenditure }\end{array}$} & \multirow[b]{2}{*}{ Healthy } & \multicolumn{2}{|c|}{ Sick } \\
\hline & & & $\begin{array}{c}\text { 0-year } \\
\text { duration }\end{array}$ & $\begin{array}{c}\text { 3-year } \\
\text { duration }\end{array}$ \\
\hline \multirow[t]{3}{*}{8} & 0 & 50.81 & 88.96 & 93.85 \\
\hline & $\$ 500$ & 10.31 & 47.60 & 60.17 \\
\hline & $\$ 1,000$ & 0.54 & 8.93 & 15.22 \\
\hline \multirow[t]{3}{*}{12} & 0 & 47.83 & 87.49 & 92.89 \\
\hline & $\$ 500$ & 9.03 & 44.63 & 57.26 \\
\hline & $\$ 1,000$ & 0.43 & 7.78 & 13.53 \\
\hline \multirow[t]{3}{*}{16} & 0 & 44.86 & 85.88 & 91.82 \\
\hline & $\$ 500$ & 7.87 & 41.69 & 54.31 \\
\hline & $\$ 1,000$ & 0.35 & 6.75 & 11.97 \\
\hline
\end{tabular}

* Age is 20.

** In 1984 dollars. 
TABLE 10: Predicted and Actual State Variables

\begin{tabular}{lccccc}
\hline \hline & \multicolumn{2}{c}{ Sickness Subsample } & & \multicolumn{2}{c}{ Full Sample } \\
\cline { 2 - 3 } \cline { 6 - 6 } & Predicted & Actual & & Predicted & Actual \\
\hline Years of schooling: & & & & & \\
$\quad$ Mean highest schooling years completed & 12.63 & 12.58 & & 13.39 & 13.40 \\
$\quad$ Percent 12 schooling years completed & 83.29 & 75.68 & & 87.08 & 83.71 \\
Percent 16 schooling years completed & 13.52 & 13.06 & & 17.71 & 25.80 \\
Mean percentage of employment & 41.86 & 42.81 & & 48.81 & 54.46 \\
Mean percentage of school attendance & 20.54 & 11.56 & & 28.65 & 25.34 \\
Mean percentage of staying at home & 37.60 & 45.63 & & 22.54 & 20.20 \\
Percent grade failing *: & & & & & \\
$\quad$ Grade 9 & 17.32 & 20.69 & & 5.61 & 13.90 \\
$\quad$ Grade 10 & 17.66 & 20.93 & & 5.85 & 6.08 \\
$\quad$ Grade 11 & 16.44 & 19.57 & & 5.22 & 5.54 \\
$\quad$ Grade 12 & 16.17 & 7.61 & & 4.97 & 3.63 \\
Mean assets at age **: & & & & & \\
21 & 2805 & 3389 & & 3548 & 4209 \\
24 & 4767 & 5257 & & 5796 & 6263 \\
27 & 9722 & 10452 & & 12466 & 12803 \\
30 & 13404 & 11823 & & 19134 & 18501 \\
Mean health expenditure & 896.6 & -- & & 850.5 & -- \\
\hline
\end{tabular}

Note: Predicted values are based on 8,000 cumulated individuals.

The sickness data include all the individuals who have been sick during the 16-year periods.

* In this case, the sickness data consists of cumulative individuals who reported sickness by the specified grade.

** In this case, the sickness subsample consists of cumulative individuals who have been sick up to age t. 
TABLE 11: Initial Health Status Effects by Initial Schooling

\begin{tabular}{lcc}
\hline \hline & Healthy at Age 16 & Sick at Age 16 \\
\hline & \multicolumn{2}{|}{ Initial Schooling Nine Years or Less } \\
\cline { 2 - 3 } Mean education attainment at age 30 & 13.17 & 12.82 \\
Mean percent survival probability at age 30 & 97.36 & 94.60 \\
Mean asset at age 30 & 17,676 & 14,822 \\
Mean health expenditure by age 30 & 834 & 892 \\
Expected present value of lifetime utility at age 16 & 186.4 & 162.5 \\
& Initial Schooling Ten Years or More \\
\cline { 2 - 3 } Mean education attainment at age 30 & 14.60 & 14.33 \\
Percent survival probability at age 30 & 98.12 & 97.08 \\
Asset at age 30 & 28,654 & 24,586 \\
Mean health expenditure by age 30 & 1030 & 1072 \\
Expected present value of lifetime utility at age 16 & 224.6 & 204.1 \\
\end{tabular}

Note: Based on a simulation of 8,000 persons. 
TABLE 12: Effect of a $\$ 2100$ College Tuition Subsidy on Selected State Variables*

\begin{tabular}{|c|c|c|c|c|c|c|c|c|c|c|c|}
\hline \multirow[b]{2}{*}{ Characteristics } & \multirow[b]{2}{*}{ All } & \multicolumn{4}{|c|}{ S Sick up to and including Age 20** } & \multirow[b]{2}{*}{ Group 4} & \multicolumn{4}{|c|}{ Healthy up to and including Age 20} & \multirow[b]{2}{*}{ Group 4} \\
\hline & & All Groups & Group 1 & Group 2 & Group 3 & & All Groups & Group 1 & Group 2 & Group 3 & \\
\hline \multicolumn{12}{|c|}{$\begin{array}{l}\text { Average highest schooling } \\
\text { years completed: }\end{array}$} \\
\hline No subsidy & 13.39 & 12.17 & 12.35 & 12.72 & 10.12 & 10.24 & 13.56 & 13.64 & 14.03 & 12.0 & 12.26 \\
\hline Subsidy & 13.81 & 12.55 & 12.76 & 13.16 & 10.16 & 10.32 & 13.97 & 13.92 & 14.45 & 12.81 & 13.15 \\
\hline \multicolumn{12}{|c|}{ Mean years in college: } \\
\hline No subsidy & 1.85 & 0.73 & 0.65 & 1.12 & 0.05 & 0.07 & 2.01 & 2.19 & 2.34 & 0.43 & 0.61 \\
\hline Subsidy & 2.20 & 1.1 & 1.15 & 1.44 & 0.05 & 0.07 & 2.34 & 2.26 & 2.82 & 1.32 & 1.58 \\
\hline \multicolumn{12}{|l|}{ Asset at age 30} \\
\hline No subsidy & 19,134 & 11,725 & 12,464 & 13,237 & 5,474 & 4,794 & 20,163 & 21,047 & 21,369 & 14,099 & 13,597 \\
\hline Subsidy & 22,608 & 13,077 & 14,026 & 14,814 & 5,483 & 4,830 & 23,822 & 24,398 & 25,873 & 16,822 & 16,056 \\
\hline \multicolumn{12}{|c|}{$\begin{array}{l}\text { Mean expected present value } \\
\text { of lifetime utility at age } 16 \text { : }\end{array}$} \\
\hline No subsidy & 185.6 & 156.5 & 162.5 & 154.8 & 142.9 & 133.9 & 189.6 & 208.6 & 198.4 & 182.0 & 174.2 \\
\hline Subsidy & 197.4 & 165.2 & 171.6 & 166.2 & 143.0 & 134.1 & 222.9 & 231.3 & 223.5 & 196.1 & 185.0 \\
\hline
\end{tabular}

Note: * The per capita cost of the subsidy is $\$ 2,247$.

** The percentage of people who were sick at least once before age 20 (including age 20): without subsidy, 12.2\%; with subsidy, 11.3\%.

1. Based on a simulation of 8,000 individuals.

2. Group 1: high ability in school and work; Group 2: high ability in school and low ability in work;

Group 3: low ability in school and high ability in work; Group 4: low ability in school and low ability in work.

3. The study and the skill endowments are drawn according to the estimated population ratio of types. 
TABLE 13: Effect of a $\$ 778$ Health Expenditure Subsidy for High School Students on Selected State Variables*

\begin{tabular}{|c|c|c|c|c|c|c|c|c|c|c|c|}
\hline \multirow[b]{2}{*}{ Characteristics } & \multirow[b]{2}{*}{ All } & \multicolumn{5}{|c|}{ Sick up to and including Age $20^{* *}$} & \multicolumn{5}{|c|}{ Healthy up to and including Age 20} \\
\hline & & All Groups & Group 1 & Group 2 & Group 3 & Group 4 & All Groups & Group 1 & Group 2 & Group 3 & Group 4 \\
\hline \multicolumn{12}{|l|}{$\begin{array}{l}\text { Average highest schooling } \\
\text { years completed: }\end{array}$} \\
\hline No subsidy & 13.39 & 12.17 & 12.35 & 12.72 & 10.12 & 10.24 & 13.56 & 13.64 & 14.03 & 12.0 & 12.26 \\
\hline Subsidy & 13.92 & 13.20 & 13.25 & 13.64 & 11.76 & 12.03 & 13.99 & 13.89 & 14.43 & 13.18 & 13.31 \\
\hline \multicolumn{12}{|l|}{ Mean years in college } \\
\hline No subsidy & 1.85 & 0.73 & 0.65 & 1.12 & 0.05 & 0.07 & 2.01 & 2.19 & 2.34 & 0.43 & 0.61 \\
\hline Subsidy & 2.29 & 1.68 & 1.72 & 2.13 & 0.34 & 0.50 & 2.35 & 2.22 & 2.79 & 1.61 & 1.86 \\
\hline \multicolumn{12}{|l|}{ Asset at age 30} \\
\hline No subsidy & 19,134 & 11,725 & 12,464 & 13,237 & 5,474 & 4,794 & 20,163 & 21,047 & 21,369 & 14,099 & 13,597 \\
\hline Subsidy & 22,603 & 16,770 & 16,312 & 19,831 & 8,519 & 13,564 & 23,230 & 23,644 & 24,621 & 18,316 & 17,983 \\
\hline \multicolumn{12}{|l|}{$\begin{array}{l}\text { Mean expected present value } \\
\text { of lifetime utility at age } 16 \text { : }\end{array}$} \\
\hline No subsidy & 195.4 & 156.5 & 162.5 & 154.8 & 142.9 & 133.9 & 200.8 & 208.6 & 198.4 & 182.0 & 174.2 \\
\hline Subsidy & 218.5 & 186.6 & 192.4 & 187.8 & 159.7 & 164.9 & 221.7 & 228.0 & 220.4 & 204.7 & 198.6 \\
\hline
\end{tabular}

Note: * The per capita cost of the subsidy is $\$ 2247$, same amount as the per capita college tuition subsidy.

** The percent sickness up to and including age 20 without subsidy is $12.2 \%$, while the percent sickness with subsidy is $9.7 \%$.

1. Based on a simulation of 8,000 individuals.

2. Group 1: high ability in school and work; Group 2: high ability in school and low ability in work;

Group 3: low ability in school and high ability in work; Group 4: low ability in school and low ability in work.

3. The skill endowments are drawn according to the population ratio of types.

4. The illness and duration are drawn from the initial health limitation distribution at age 16. 
Figure 1: Stochastic Shocks and Decisions
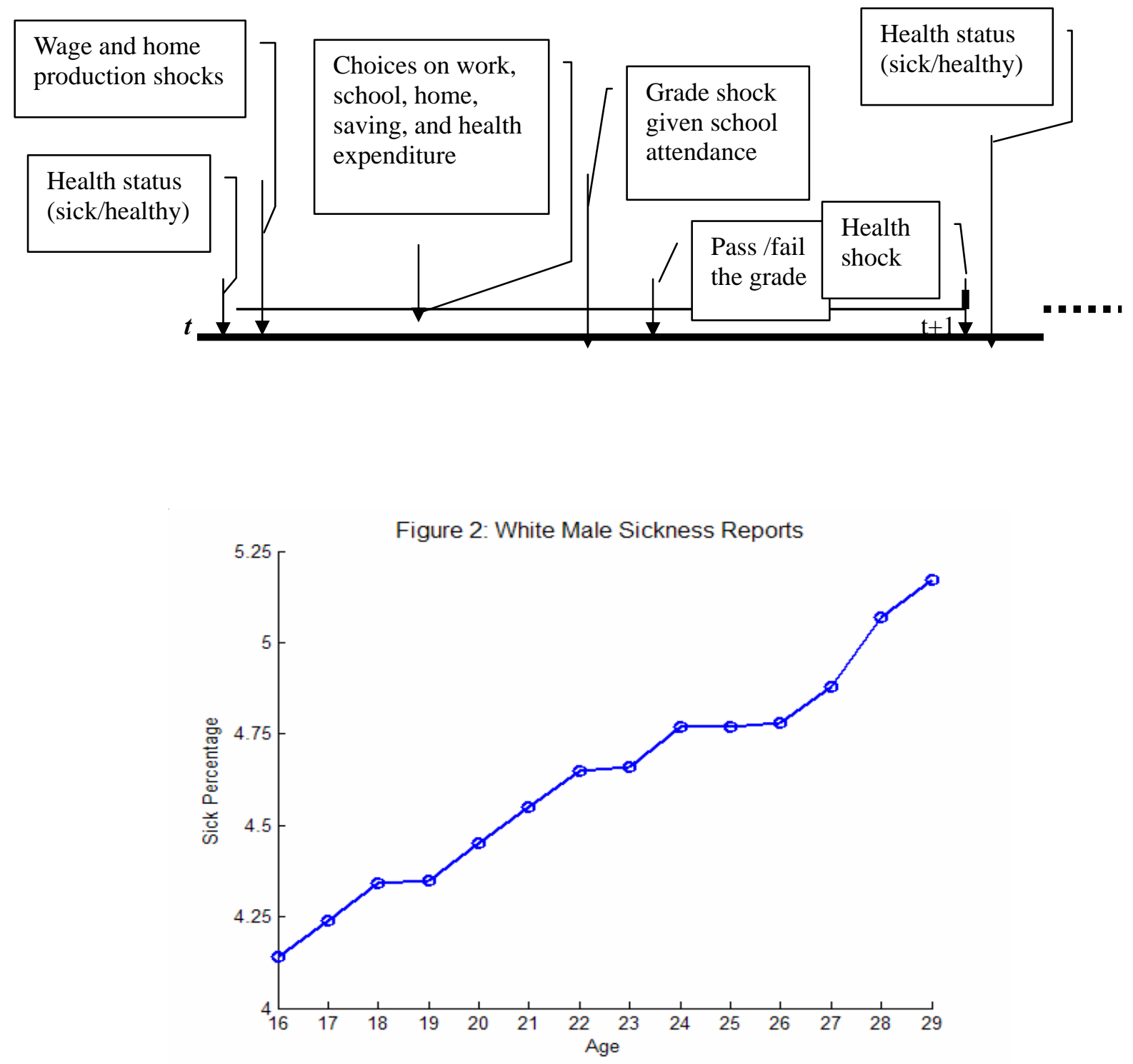
Figure 3a: Predicted and Actual Choice Selections by Age

(Full Sample)
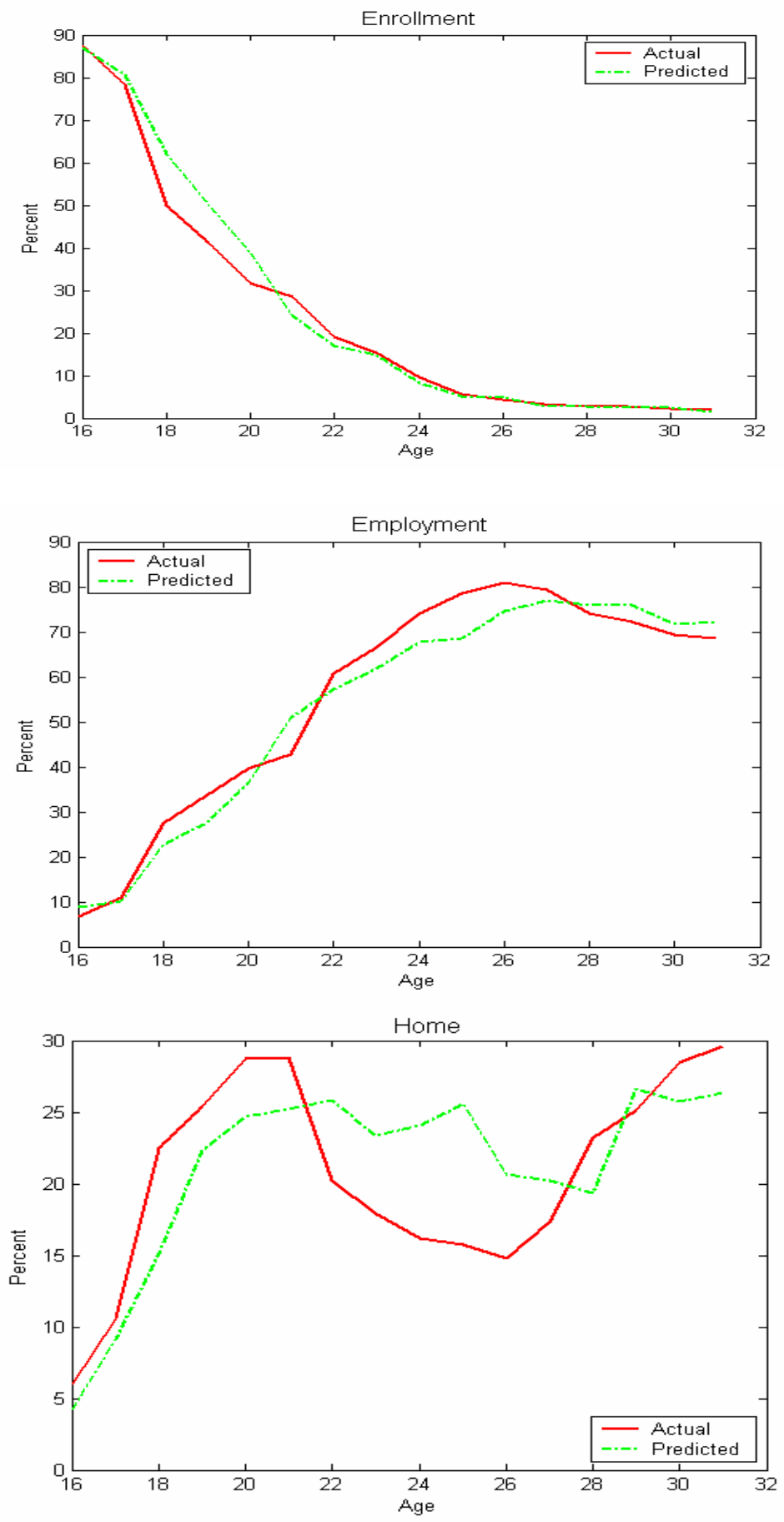
Figure 3b: Predicted and Actual Mean Percent Choice Selections by Age (Sickness Subsample)
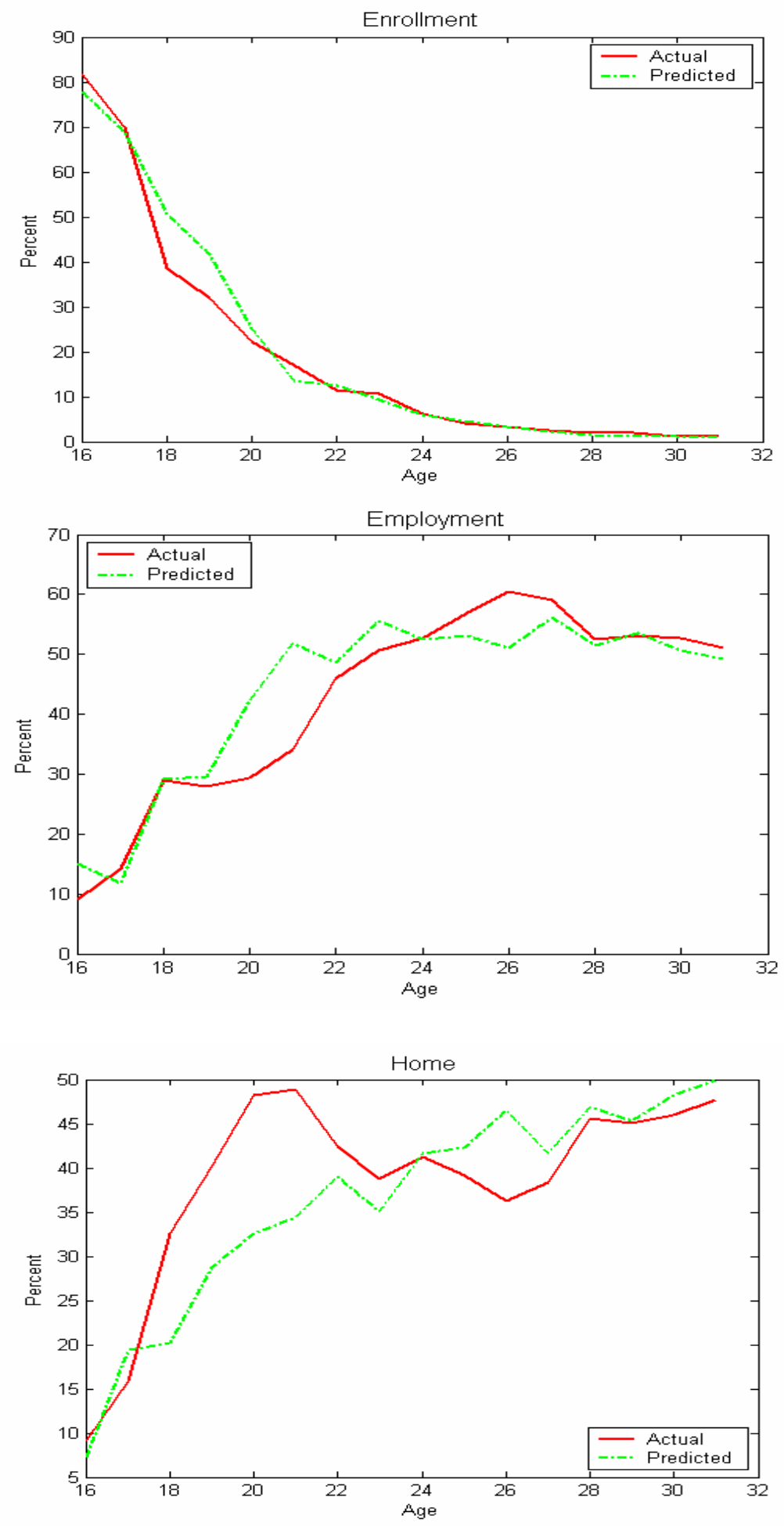
Figure 4a: Predicted and Actual Mean Assets by Age (Full Sample)

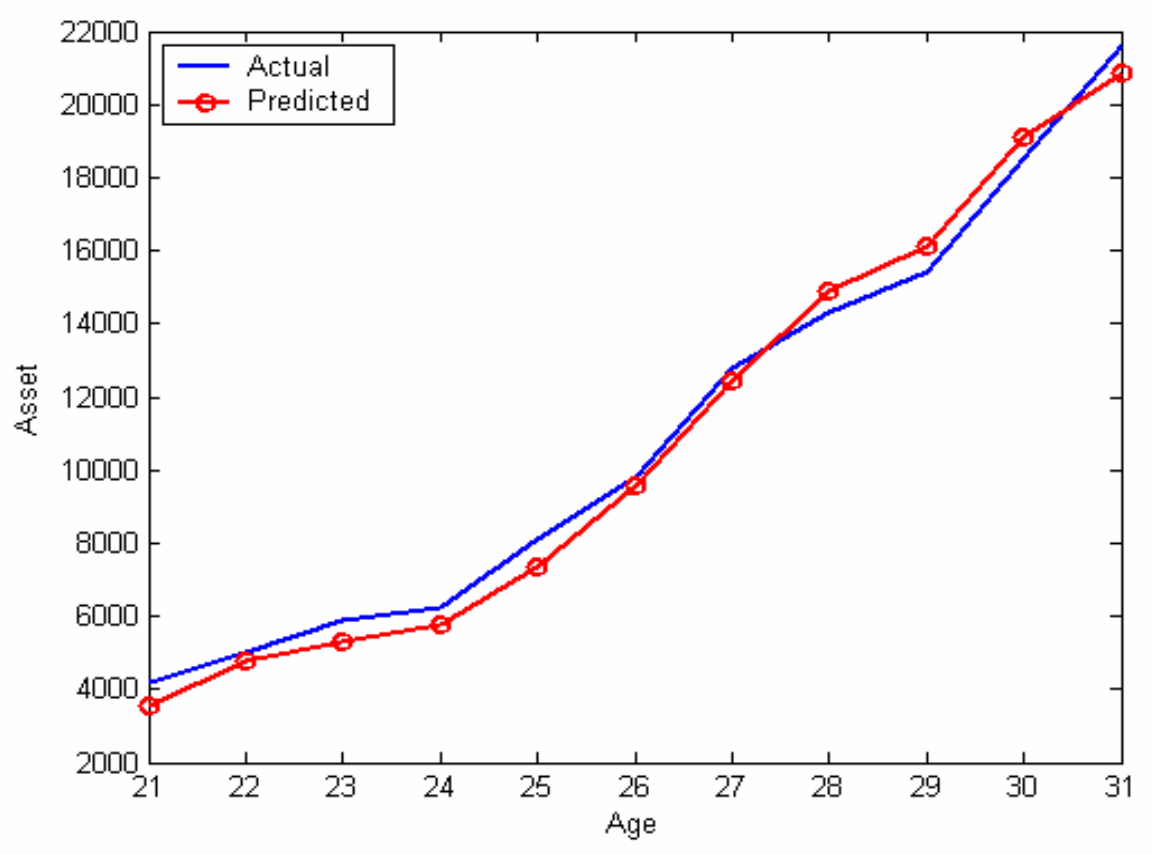

Figure 4b: Predicted and Actual Mean Assets by Age (Sickness Subsample)

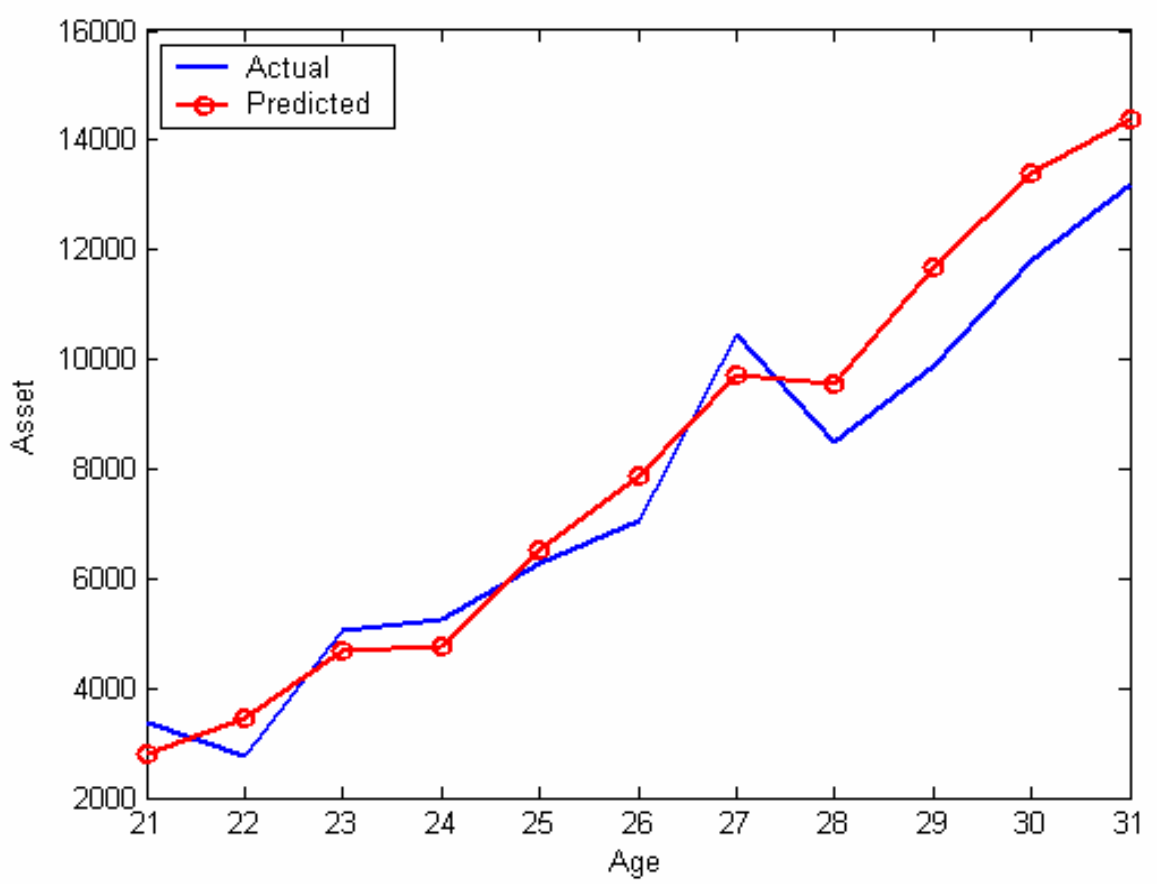


Figure 5: Predicted and Actual Sick Percentage

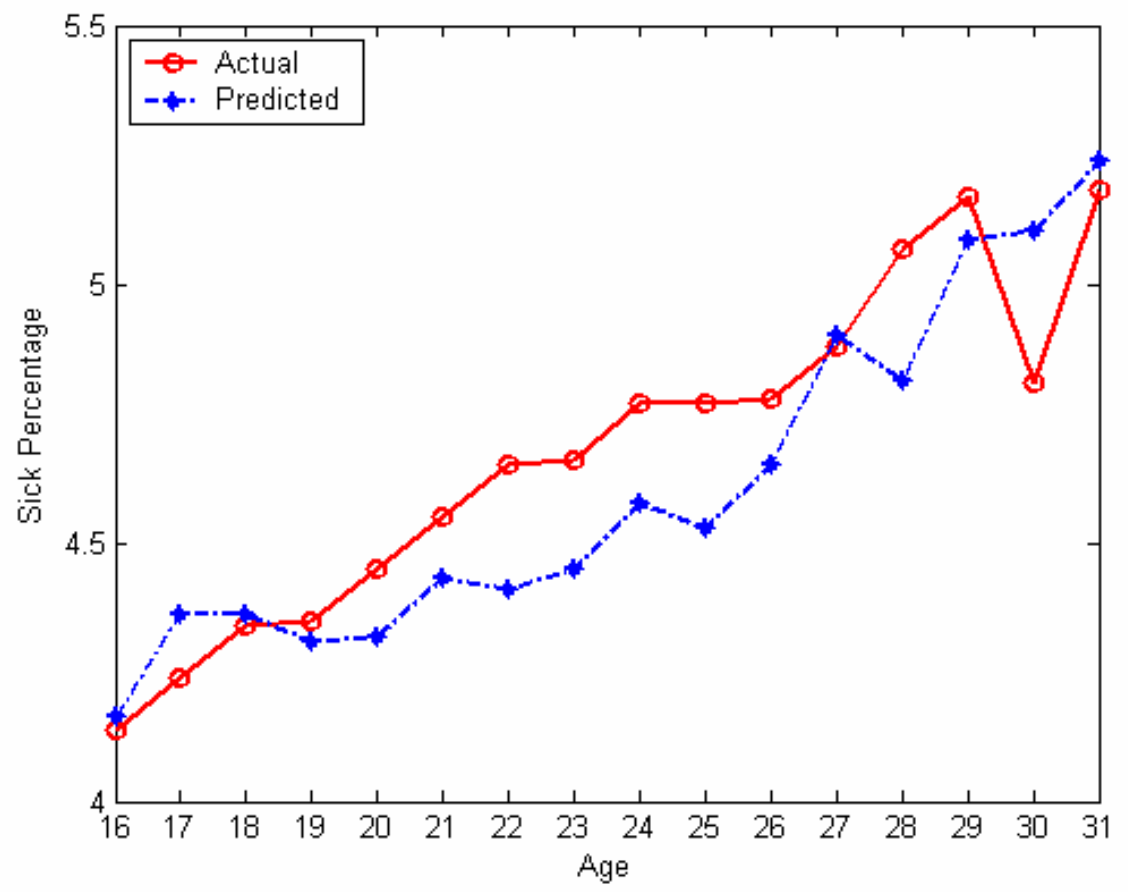

Figure 6: Predicted Mean Health Expenditure and Percentage of Zero Health Expenditure

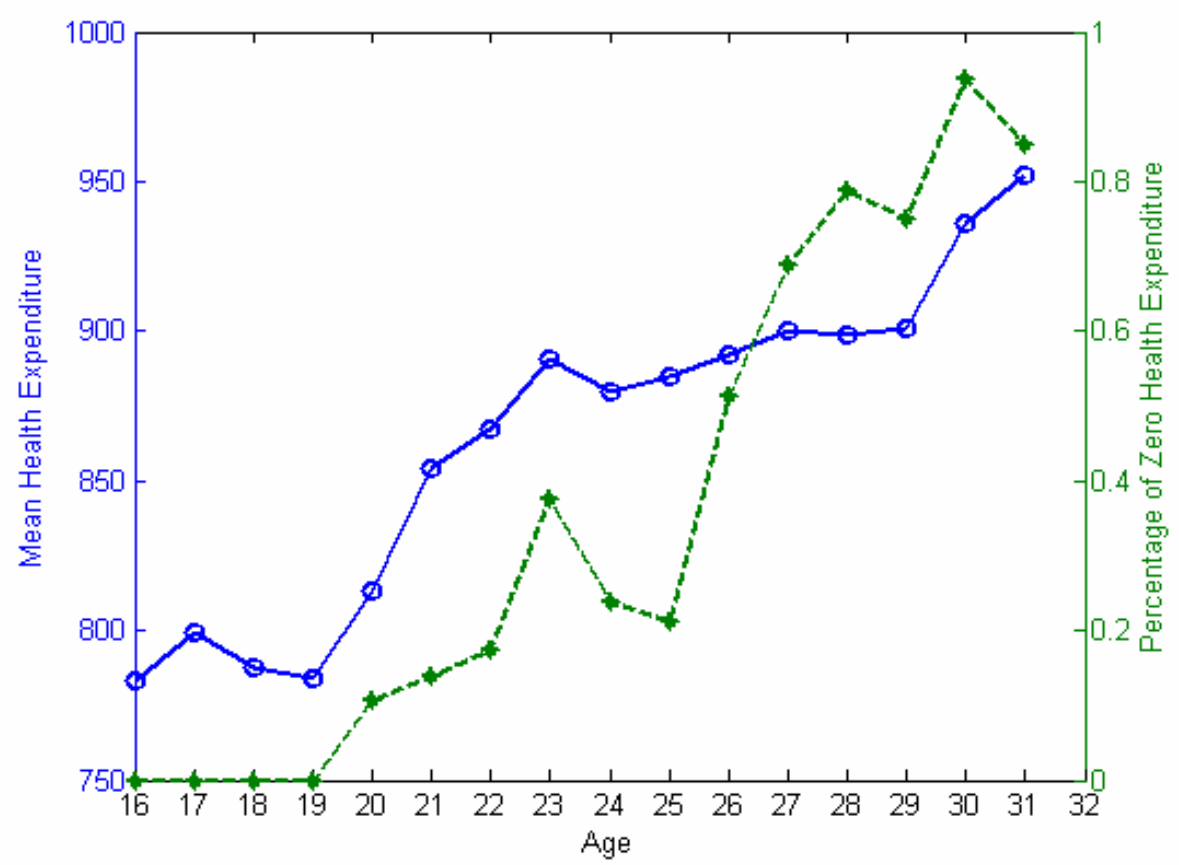

